\title{
GFAP-directed Inactivation of Men1 Exploits Glial Cell Plasticity in Favor of Neuroendocrine Reprogramming
}

Suzann Duan ${ }^{1}$, Travis W. Sawyer ${ }^{2}$, Ricky A. Sontz ${ }^{1}$, Bradley A. Wieland ${ }^{1}$, Andres F. Diaz ${ }^{1}$, and Juanita L. Merchant ${ }^{1 *}$

${ }^{1}$ University of Arizona College of Medicine, Department of Medicine, Division of Gastroenterology, Tucson, AZ, 85724 USA; ${ }^{2}$ Wyant College of Optical Sciences, University of Arizona, Tucson, AZ, 85724 USA

Grant Support: R01 DK45729-27 to JLM.

\section{*Correspondence:}

Juanita L. Merchant

University of Arizona

1515 N. Campbell Ave.

Tucson, AZ 85724

jmerchant@arizona.edu

(520) 626-7897

(520) 626-1291

Author Contributions: SD contributed to the design and execution of experiments, analysis and interpretation of data, and drafting the manuscript. TWS performed ex vivo imaging studies and wrote the program for generating heatmaps. RAS oversaw mouse breeding and genotyping. BAW assisted with cell culture studies. AFD assisted with immunohistochemical staining of mouse tissue slides. JLM conceived the study premise, provided feedback on data interpretation, and contributed to drafting and editing the manuscript.

Disclosures: The authors have no conflicts of interest to disclose.

Data Transparency: Data will be made available upon written request. 


\section{ABBREVIATIONS:}

BG: Brunner's glands

ChgA: Chromogranin A

Gcg: Glucagon

GEP-NENs: gastroenteropancreatic neuroendocrine neoplasms

GFAP: Glial fibrillary acidic protein

Grp: Gastrin-releasing peptide

Ins 1: Insulin

MEN1: Multiple endocrine neoplasia 1

nPan: Normal pancreas

nPit: Normal pituitary

PCA: Principal Component Analysis

PitNET: Pituitary neuroendocrine tumor

PNEC: Pancreatic neuroendocrine carcinoma

PNET: Pancreatic neuroendocrine tumor

Prl: Prolactin

SMA: Smooth muscle actin

siRNA: small interfering RNA

Sst: Somatostatin

Syp: Synaptophysin

Vip: Vasoactive intestinal peptide 


\begin{abstract}
BACKGROUND \& AIMS: Efforts to characterize the signaling mechanisms that underlie gastroenteropancreatic neoplasms (GEP-NENs) are precluded by a lack of comprehensive model systems that recapitulate pathogenesis. Investigation into a potential cell-of-origin for gastrinsecreting NENs revealed a role for enteric glia in neuroendocrine cell specification. Here we investigated the hypothesis that loss of menin in glial cells stimulated neuroendocrine differentiation and tumorigenesis. METHODS: Using Cre-lox technology, we generated a conditional glial fibrillary acidic protein-directed Menl knockout $\left(G F A P^{\triangle M e n l}\right)$ mouse model. Cre specificity was confirmed using a tdTomato reporter. GFAP ${ }^{\triangle M e n 1}$ mice were evaluated for GEPNEN development and neuroendocrine cell hyperplasia. siRNA-mediated Men1 silencing in a rat enteric glial cell line was performed in parallel. RESULTS: $G F A P^{\Delta M e n 1}$ mice developed pancreatic NENs, in addition to pituitary prolactinomas that phenocopied the human MEN1 syndrome. $G F A P^{\triangle M e n 1}$ mice exhibited gastric neuroendocrine hyperplasia that coincided with a significant loss of GFAP expression. Mechanistically, Men1 deletion induced reprogramming from a mature glial phenotype toward a neuroendocrine lineage. Furthermore, blockade of Hedgehog signaling in enteric glia attenuated neuroendocrine hyperplasia by restricting the neuroendocrine cell fate. CONCLUSIONS: GFAP-directed Men1 inactivation exploits glial cell plasticity in favor of neuroendocrine differentiation.
\end{abstract}

KEYWORDS: MEN1; neuroendocrine neoplasms; glial fibrillary acidic protein; Hedgehog signaling 


\section{INTRODUCTION}

Gastroenteropancreatic neuroendocrine neoplasms (GEP-NENs) comprise a heterogeneous group of malignancies showing an increase in incidence and prevalence across the Unites States ${ }^{[1,2]}$. GEP-NENs are comprised of endocrine-producing cells and include gastric carcinoids, gastrinomas, and pancreatic neuroendocrine tumors (NETs) ${ }^{[3]}$. The development of GEP-NENs is frequently associated with sporadic and inherited mutations in the Multiple Endocrine Neoplasia I (MEN1) gene ${ }^{[4]}$. Inactivation of the MEN1 locus causes loss of the tumor suppressor protein menin and coincides with the development of endocrine tumors in the pancreas, pituitary, and upper GI tract ${ }^{[5]}$. Patients carrying a MEN1 mutation are predisposed to developing gastrinomas, a GI NET that produces excess levels of gastrin, a peptide hormone that stimulates acid secretion, inflammation, and proliferation [6,7,8,9]. Such MEN1-associated gastrinomas preferentially develop in Brunner's glands located within the duodenal submucosa, with an estimated $>50 \%$ of MEN1 gastrinomas exhibiting lymph node metastases at the time of diagnosis $[10,11]$.

Loss of menin function is a critical event underlying the formation of MEN1 gastrinomas however, the signaling cues that regulate menin-mediated suppression of gastrin remain elusive. Homozygous deletion of Menl in utero is embryonically lethal in mice, whereas heterozygous inactivation promotes endocrine tumors of the pancreas and pituitary, but not in the GI tract ${ }^{[12]}$. Importantly, these studies did not identify potential cells-of-origin for tumor development. Subsequently, we reported the development of the first genetically engineered mouse model that displays gastric carcinoids ${ }^{[13]}$. Conditional deletion of Menl from the GI tract epithelium using the Villin Cre transgene on a somatostatin-null genetic background resulted in antral G cell hyperplasia, hypergastrinemia, and gastric carcinoids ${ }^{[13]}$. Systemic gastric acid suppression using a proton pump inhibitor accelerated carcinoid development and coincided with the emergence of 
hyperplastic gastrin-expressing glial cells within the lamina propria of the duodenum ${ }^{[14]}$. The plasticity of glial cells directed towards an endocrine phenotype coincided with decreased menin [14]. Taken together, these observations suggest that hyperplastic G-cells might emerge from reprogrammed neural crest-derived cells rather than from endoderm-derived enteroendocrine cells. Indeed, prior studies have shown that multipotent glial cells can generate neuroendocrine cells during normal development ${ }^{[15]}$ and upon overexpression of oncogenes such as $M Y C N{ }^{[16]}$. Therefore, we tested the hypothesis that loss of menin in enteric glial cells promotes neuroendocrine cell differentiation. Here we show that conditional deletion of Men 1 in GFAPexpressing glial cells results in NEN development in the pituitary and pancreas, in addition to neuroendocrine hyperplasia in the stomach. These events coincided with loss of the glial phenotype and emergence of an endocrine phenotype with tissue-specific hormone expression, suggesting a direct role for glial cell reprogramming upon removal of menin. 


\section{RESULTS}

\section{GFAP ${ }^{4 M e n 1}$ mice develop pancreatic neuroendocrine neoplasms (PNENs).}

To determine whether loss of menin in glial cells was sufficient to drive the development of GEP-NENs, we used Cre-lox technology to conditionally delete Menl under the control of the glial fibrillary acidic protein (GFAP) promoter $\left(G F A P^{4 M e n I}\right)$. By 18-24 months of age, 7 of 12 GFAP $P^{\triangle M e n 1}$ mice developed macroscopic lesions throughout the pancreas (Table 1). Histological analysis of the pancreas identified significant islet hyperplasia and features characteristic of neuroendocrine neoplasms (Figure 1A). Pancreatic lesions varied from poorly differentiated with a solid sheet-like morphology to highly differentiated with a rosette pattern (Figure 1B-D). Consistent with their unique histology, highly differentiated neoplasms exhibited cytoplasmic or absent menin expression (Figure 1E) and strong immunoreactivity for the neuroendocrine markers synaptophysin (Syp) and chromogranin A (ChgA), in addition to the alpha cell specification factor iroquois homeobox protein 2 (Irx2) (Figure 1E and F). Poorly differentiated tumors also exhibited strong nuclear expression of Irx 2 with a sparse number of cells displaying immunoreactivity for Syp (Figure 1G). Based on the mitotic index used to categorize human pancreatic NENs ${ }^{[17]}$, we stained GFAP ${ }^{\triangle M e n l}$ neoplasms for Ki-67 and classified the tumors as PNETs $(<2 \%$ per high power field, HPF) (Figure 1H and I) or PNECs ( $>20 \%$ per HPF) (Figure 1J). Further characterization of highly differentiated PNETs revealed the presence of both hyperplastic insulin-expressing betacells and glucagon-expressing alpha-cells (Figure 1K-M). Evaluation of neuroendocrine transcript expression revealed a 10-fold increase in ChgA and 5-fold increase in Syp mRNA, however no significant differences in hormone expression were observed between wild type pancreas and the PNETs (Figure 1N). Next, we evaluated whether GFAP ${ }^{\triangle M e n l}$ PNENs express GFAP. As previously reported, GFAP expression were primarily localized to the periphery of islets in both wild type 
and $G F A P^{\triangle M e n 1}$ mice ${ }^{[18]}$, however expression was uniquely lost surrounding PNETs (Figure 1O). In comparison, PNECs exhibited robust GFAP expression. Consistent with this, the expression of glial transcripts Gfap and $S 100 b$ were significantly lower in PNETs compared to the pancreas of wild type mice, while Men1 mRNA exhibited a trending decrease (Figure 1P). In summary, development of well-differentiated PNETs in this model coincided with loss of GFAP expression from the periphery of normal endocrine cells.

\section{GFAP ${ }^{4 M e n 1}$ mice develop PitNETs that phenocopy human MEN1 prolactinomas.}

Following our observation of hydrocephalus-like neurological symptoms in a subset of $G F A P^{\triangle M e n 1}$ mice, we further investigated the brain for potential effects of GFAP-directed Men1 inactivation. GFAP is the main intermediate filament protein in brain astrocytes and related cell types such as enteric glial cells where it is strongly expressed ${ }^{[19]}$. Moreover, GFAP marks nestin ${ }^{+}$ subventricular neural stem cells ${ }^{[20-22]}$ and interacts with menin ${ }^{[23,24]}$. Fifty percent of $G F A P^{\triangle M e n I}$ mice exhibited hemorrhagic pituitary tumors, with the phenotype being nearly exclusively sexdependent. Female GFAP ${ }^{\triangle M e n 1}$ mice (15 of 22 or $68 \%$ ) developed macroscopic pituitary adenomas as early as 15 months of age (Table 1, Figure 2A and B). Subsequent immunostaining of GFAP $\triangle M e n 1$ adenomas demonstrated diffuse immunoreactivity for synaptophysin and chromogranin A (Figure 2C). Strong staining for prolactin and the pituitary-specific marker Pit-1 showed these tumors to be prolactinomas (Figure 2D and E). Additionally, variable Ki-67 expression appeared to inversely correlate with the expression of neuroendocrine markers, with stronger neuroendocrine status associated with lower Ki-67 staining (Figure 2E). Further evaluation of GFAP and menin expression in $G F A P^{\triangle M e n 1}$ prolactinomas showed absent GFAP staining and low expression of menin within the tumor compared to the adjacent hypothalamus 
(Figure 2F and G). Similar to the previous observations in PNETs, Gfap and Men1 mRNA expression was significantly reduced in prolactinomas compared to wild type pituitary (Figure 2H). As expected, the neuroendocrine transcripts $C h g B$, Syp, and Enolase 2 (Eno2) were significantly elevated in $G F A P^{\triangle M e n 1}$ pitNETs compared to wild type pituitary. Additionally, mRNA levels of the prolactin and vasoactive intestinal peptide (Vip) hormones were 15-fold higher in pitNETs (Figure 2I). To determine whether GFAP-negative GFAP $\triangle M$ men 1 pitNETs share features with neural stem cells, we generated tumor neurospheres from a GFAP $\triangle M e n 1$ pituitary prolactinoma. Subsequent immunostaining of $G F A P^{\triangle M e n 1}$ tumor neurospheres revealed that tumor cells co-expressed prolactin and the neural stem cell markers Sox 2 and Nestin, indicating that the hormone-expressing tumor cells arose from a neural stem cell lineage (Figure 2J).

\section{Hyperplastic reprogramming of the gastro-intestinal epithelium in $G F A P^{A M e n 1}$ mice.}

To determine whether loss of menin in enteric glia supports the development of NENs in the luminal gastrointestinal (GI) tract, we evaluated the stomach and proximal small intestine of $G F A P^{\triangle M e n 1}$ mice for changes in enteroendocrine cell numbers and composition. Although no gastrinomas or small intestinal NENs were observed at 18-24 months of age, GFAP ${ }^{\triangle M e n l}$ mice showed hyperplastic changes in both the corpus and gastric antrum by nine months of age (Figure 3A). Further analysis of neuroendocrine marker expression revealed a $\sim$ two-fold increase in $C h g A$ transcripts in both the corpus and gastric antra of $G F A P^{\triangle M e n 1}$ mice, while no differences in mRNA levels were observed in the proximal duodenum (Figure 3B). Subsequent immunostaining confirmed increased $\operatorname{Chg} A$ expression in the proximal and distal stomach (Figure 3C). Moreover, the GFAP ${ }^{\Delta M e n 1}$ mice exhibited a significant increase in antral Syp expression (Figure 3D). Elevated Syp protein in gastric antra was further confirmed by immunostaining (Figure 3E). As menin is a 
known repressor of gastrin gene expression and its loss in intestinal epithelium was previously shown to stimulate hypergastrinemia in Villin Cre; Men $1^{F l / F L}$ mice ${ }^{[13]}$, we assessed whether deletion of menin in enteric glia similarly induced gastrin hormone expression. Consistent with the previous increases in neuroendocrine marker expression, we observed a significant increase (three-fold) in gastrin mRNA and gastrin immunostaining in the antra of GFAP $\triangle M e n 1$ mice (Figure 3F and $\mathrm{G})$. Therefore, conditional deletion of menin in enteric glial cells stimulates neuroendocrine hyperplasia that is specific to the stomach. However unlike the islets and pituitary, glial-directed Men1 deletion was insufficient to convert the hyperplastic endocrine cells into NETs in this model.

\section{Glial cell reprogramming occurs in $G F A P^{\Delta M e n 1}$ mice .}

Since NET development in the pituitary and pancreas coincided with an apparent loss of GFAP expression, we examined the impact of Menl deletion on glial cell fate in vivo. We generated GFAP $\triangle M e n 1$ mice expressing a GFAP Cre tdTomato reporter (Figure 4A). Fluorescent imaging of both whole tissue mounts and frozen sections of the GI tract confirmed expression in enteric glial cells. Surprisingly, ex vivo fluorescent imaging of tissues from $G F A P^{\triangle M e n 1}$ mice revealed a $\sim 4$-fold reduction in the tdTomato signal across the upper GI tract compared to wild type mice (Figure 4B and C). Fluorescent imaging indicated appropriate localization of the tdTomato signal to the lamina propria, submucosa and myenteric plexus ganglia (Figure 4D and E). Further imaging of frozen tissue sections confirmed near-loss of tdTomato fluorescence in the mucosa and lamina propria, while some signal was still retained in the submucosal and myenteric plexi (Figure 4E). Therefore, deletion of Menl in GFAP+ cells extinguished GFAP expression.

A prior study showed that GFAP and menin proteins interact in astrocytes ${ }^{[23]}$. To test whether this interaction also occurs in glial cells we performed co-immunoprecipitation using 
extracts from a rat enteric glial cell line (EGC) and confirmed interactions between GFAP and menin in whole cell lysates as well as nuclear and cytoplasmic fractions (Figure 4F). Although intermediate filaments including GFAP are elaborate cytoskeletal structures residing in the cytoplasm, their expression also occurs in the nucleus and peri-nuclear regions of various cell types [25-27]. Similarly, the subcellular localization of menin is dynamic with its movement in and out of the nucleus regulated by multiple factors ${ }^{[14,28,29]}$. Accordingly, menin and GFAP interactions occurred in both the nuclear and cytoplasmic cellular compartments (Figure 4F). Moreover siRNA-mediated Men1 silencing, also decreased S100b, another mature glial cell marker along with GFAP (Figure 4G and $\mathrm{H}$ ), indicating a role for menin in regulating glial cell identity by modulating GFAP.

\section{Transcriptome-wide analysis of gastric neuroendocrine hyperplasia and NENs supports glial-to-neuroendocrine reprogramming.}

Since glial-specific deletion of menin was sufficient to drive NEN formation in the pituitary and pancreas but not in the stomach or intestine, we used RNA-Seq to identify the molecular pathways that might contribute to the transition from neuroendocrine hyperplasia to NEN development. GFAP ${ }^{\triangle M e n 1}$ pitNETs, gastric antrum, and their respective wild type (WT) counterparts were submitted for bulk RNA sequencing. Principal Component Analysis confirmed a higher degree of divergence between pitNETs and normal WT pituitaries compared to hyperplastic GFAP $\triangle M e n 1$ and WT antra (Supplementary Figure 1A). Accordingly, the number of significant differentially expressed genes (DEGs) was ten-times higher in pitNETs compared to antral tissues (Figure 5A and B). As anticipated, a number of genes related to neuroendocrine differentiation were upregulated in both datasets, e.g. Grp, Vip, Syp, and Ncam1/2 in antra and Prl, 
Chgb, Eno2, Cckbr, Vip, and Ascl2 in pitNETs (Figure 5C and D). Genes associated with the neuroglial lineage were significantly upregulated in $G F A P^{\triangle M e n 1}$ tissues compare to WT controls (Figure 5E and F). Furthermore, a majority of upregulated antral genes were correlated with neural differentiation and acquisition of a neuronal cell fate, including $N g f r$, Elav3/4, Nrsn1/2, Phox 2b, Nos1, Tubb3, Uchl1, Ret, and Hoxb (Figure 5E). PitNETs also exhibited increased expression of neural-specific transcripts, e.g. Elav3/4, Nrsn 1/2, and Tubb3 and this coincided with significant downregulation of astroglial lineage genes, e.g. Gfap, Slc1a3, Cd40, Aldh111, Aqp4, Olig2, P2ry12, Sox9, and Notch1, (Figure 5F). Furthermore, pitNETs exhibited increased expression of neural crest cell transcripts related to stemness, including Vim, Fabp7, and Sox11, as well as genes involved in cell cycle inhibition and differentiation (e.g. Cdknla, Cdkn2a, and Cend1), as well as tissue development (e.g. Shh, Nog, Bmp2/7, Bdnf, and Ezh2) (Figure 5F and Supplementary Figure 1B and C). Increased expression of genes related to NET differentiation and cellular senescence were validated by quantitative PCR of NETs and age-matched WT tissues (Supplementary Figure $1 \mathrm{D}$ and $\mathrm{E})$.

Both datasets showed an enrichment of genes involved in neuroactive ligand receptor interaction and synaptic signaling pathways (Figure 5G and Supplementary Figure 1F). A number of genes upregulated in pitNETs were mapped to the Hedgehog signaling pathway, which was consistent with increased expression of Shh mRNA and ciliary motor proteins known to facilitate transduction of Hedgehog signaling (Figure 5G and Supplementary Figure 1D and G). Further, increased expression of neuroendocrine and neural-lineage genes in $G F A P^{\triangle M e n 1}$ antral extracts coincided with downregulation of cytokeratins and immune-related transcripts (Supplementary Figure $1 \mathrm{H}$ and $\mathrm{I})$. 
Enteric neurons express gastrin-releasing peptide (Grp) ${ }^{[30]}$, which is the most significantly upregulated transcript in $G F A P^{\triangle M e n 1}$ gastric antra, providing a direct mechanism for increased antral gastrin levels in these mice. To confirm that GFAP-directed deletion of Men 1 stimulates Grp expression leading to $\mathrm{G}$ cell expansion, we stained the antra of $G F A P^{\triangle M e n 1}$ mice for Grp. As anticipated, GFAP $\triangle M e n 1$ mice exhibited increased antral expression of Grp. Furthermore, Grp expression co-localized with Syp in the epithelial mucosa (Figure 5H). To assess whether loss of menin in enteric glial cells (EGCs) directly stimulates the expression of Grp and Syp, Men 1 was knocked down in rat EGCs, which induced both Grp and Syp mRNA expression (Figure 5I). Taken together, these results demonstrate that Menl deletion suppresses the mature glial phenotype in favor of a neuroendocrine phenotype, perhaps through loss of GFAP.

\section{Impairment of Sonic hedgehog (Shh) signaling in enteric glial cells attenuated neuroendocrine cell hyperplasia in $G F A P^{4 M e n 1}$ mice.}

Hedgehog signaling mediated by primary cilia is known to promote premature differentiation of neural progenitor cells toward the neuronal lineage ${ }^{[31]}$. As $G F A P^{\triangle M e n 1}$ pitNETs exhibited significantly elevated Shh transcript levels, we investigated whether loss of Kif3a, a ciliary motor protein required for Shh signal transduction, blocks $G F A P^{\triangle M e n 1}$ glia from developing a neuroendocrine phenotype. To further stimulate gastric neuroendocrine hyperplasia, GFAP $\triangle$ Men 1 mice were crossed onto a somatostatin null $\left(S s t^{-\wedge}\right)$ background. Sst suppresses hormone secretion, including gastrin, thus removal of Sst-mediated feedback inhibition increases gastrin levels ${ }^{[14]}$. The effect of Kif3a deletion on neuroendocrine hyperplasia was accomplished by breeding $G F A P^{\triangle M e n 1} ; S s t^{-\leftarrow}$ mice onto a $K i f 3 a^{F L / F L}$ genetic background (GFAP $\left.\triangle M e n 1 ; \triangle K i f 3 a\right)$ (Figure 6A). Shortened primary cilia were shown by immunostaining for acetylated tubulin-positive hair-like 
projections on enteric glia. Compared to WT mice, GFAP $4 M e n 1 ; 4 K i f 3 a$ mice exhibited shortened primary cilia on $\mathrm{GFAP}^{+}$glial cells in the gastric antrum (Figure 6B). Hedgehog signaling is mediated through activation of the Gli1/2/3 family of transcriptional effectors ${ }^{[32]}$. Thus, we assessed whether deleting Kif3a affects the expression of Gli2, a known suppressor of gastrin gene expression in antral G cells ${ }^{[33]}$. Whereas GFAP-directed Men1 deletion increased antral Gli2 expression, loss of Kif3a reduced the expression of Gli2 protein and transcript (Figure 6C and D). We next assessed whether GFAP ${ }^{\triangle M e n 1 ; \triangle K i f 3 a}$ mice showed reduced GFAP-tdTomato fluorescence compared to GFAP $\triangle M e n 1$ mice with intact primary cilia. As expected, loss of GFAP-tdTomato fluorescence was reversed in the GFAP 4 Men1;4Kif3a mice (Figure $6 \mathrm{E}$ and F). Kif3a deletion was associated with a trending increase in antral Gfap mRNA expression (Figure 6G). To determine the effect of Kif $3 a$ deletion on enteroendocrine cell composition, we analyzed the neuroendocrine -related transcripts in the antrum and proximal duodenum after sequential deletion of Sst, Men1, and Kif3a genes. Compared to wild type and Sst null mice, deleting Men 1 significantly increased the expression of ChgA and Syp mRNA in the gastric antra, as anticipated (Figure 6H and I). Deleting Kif3a in the presence of Sst and Menl deletions inhibited the previously observed increase in antral neuroendocrine transcripts induced antral expression of gastrin transcript and gastrin peptide in $G F A P^{\triangle M e n l}$ mice. The induction was mitigated after Kif3a was deleted in (Figure $6 \mathrm{~J}$ and $\mathrm{K}$ ). Thus, blockade of Shh-mediated signaling in enteric glia attenuated neuroendocrine cell hyperplasia in the distal stomach. 


\section{DISCUSSION}

Progress in understanding GEP-NET pathogenesis is impeded by a lack of comprehensive in vivo models, in part due to tissue heterogeneity from which the neoplasms arise, and the absence of consistent driver mutations preceding malignancy ${ }^{[34]}$. We report here that conditional deletion of the tumor suppressor protein Menl (menin) in $\mathrm{GFAP}^{+}$glial cells induced neuroendocrine cell hyperplasia and the development of neuroendocrine tumors in the pituitary and pancreas.

Neuroendocrine cell hyperplasia and NET development coincided with an unexpected loss of the mature glial cell phenotype and induction of neuronal and neuroendocrine-lineage genes in stomach, pancreas and pituitary. We demonstrated that deletion of Menl induced loss of GFAP in the GI tract and in NETs by immunostaining, qPCR, and through tracking of GFAP-tdTomato positive cells. In contrast to NETs which exhibited a global reduction in GFAP staining, tdTomato signal, and mRNA expression, the gastric antra of $G F A P^{\triangle M e n l}$ mice showed reduced GFAP-reporter expression but did not exhibit significant loss of GFAP at the transcript level. This observation may be explained in part by the fact that menin interacts and colocalizes with GFAP ${ }^{[23]}$. Hence, it remains a possibility that conditional deletion of menin in $\mathrm{GFAP}^{+}$glial cells disrupts proper localization of GFAP leading to altered glial cell identity creating a microenvironment sufficient for tumor formation in the islet pancreas and pituitary but not in the gastric antrum or duodenum.

Similar to previous reports of Menl-deleted mouse models, we did not observe the development of small intestinal gastrinomas, suggesting that additional genetic or microenvironmental factors are required to stimulate neoplastic transformation in these tissues [12,35-39]. To identify molecular features that might inform the transition from neuroendocrine hyperplasia to NET development, we compared the transcriptomes of hyperplastic antral tissues with well differentiated NETs arising in this model. While glial-directed Menl deletion induced 
neural differentiation pathways at both tissue sites, NETs exhibited loss of more astroglial-lineage genes, e.g. Gfap, Aldh1l1, Slc1a3, Aqp4, and Olig1 and downregulation of factors involved in directing astrogliogenesis, e.g. Nfia, Nfib, Zfp36l1, Id3, and Sox9 [40-44]. Thus, the transition from a glial-to-neuronal cell phenotype appears to promote the hyperplastic neuroendocrine and tumor development. In support of this, NETs exhibit increased expression of genes associated with neural stem and progenitor cell status, e.g. Fabp7, Vim, Sox11, and Hoxb genes, and upregulation of neural crest-secreted factors that favor neurogenesis and restrict a glial cell fate, e.g. Bmp2, Bmp7, and $S h h^{[45-51]}$. A number of these signaling factors are components of the Hedgehog signaling pathway, known to play a role in directing neuronal differentiation at the expense of restraining gliogenesis and glial cell maturation ${ }^{[31]}$. A role for menin in this process is highlighted by the fact that menin is a known epigenetic repressor of both canonical and non-canonical Hedgehog signaling ${ }^{[52,53]}$. Moreover, these studies demonstrate that blockade of Hedgehog signaling attenuate islet cell proliferation in a Men 1 -mediated insulinoma mouse model ${ }^{[53]}$. Consistent with these reports, we found that attenuation of Shh signaling by disrupting primary cilia on glial cells reduced neuroendocrine hyperplasia by restricting neural differentiation of $M e n 1^{F L / F L}$ glial cells.

Enteric glia exhibit a high degree of cellular plasticity within the context of their specific microenvironment ${ }^{[38,54]}$. Indeed, they have been identified as a source of neural progenitor cells and are able to de-differentiate and trans-differentiate to other cell lineages under explicit physiological and in vitro conditions ${ }^{[15,16,55-58]}$. However, it remains unknown whether neural crest cells or their progeny can undergo context-specific reprogramming, e.g., by acquiring MEN1 mutations, and giving rise to neuroendocrine cells with hormone-secreting capabilities. Evidence to support glial or astrocytic reprogramming would challenge the long-standing paradigm that neuroendocrine tumors in the GI tract develop from enteroendocrine cells that originate from $\operatorname{Lgr}^{+}$ 
stem cells of endodermal origin ${ }^{[59]}$. Previous work by our group demonstrated that non-cell autonomous loss of menin protein in enteric glial cells induces gastrin hormone expression ${ }^{[13,14]}$. Furthermore, human duodenal NETs are known to express glial cell markers, with some cells within the tumor exhibiting expression of both the neuroendocrine marker Syp and the glialspecific protein $\mathrm{S} 100 \mathrm{~b}^{[14,60]}$. We recently used digital spatial profiling to characterize neuroglial features in a small subset of human duodenal NETs ${ }^{[60]}$. Tumors exhibited reduced expression of mature neuronal and glial cell markers compared to the adjacent Brunner's glands from which $60 \%$ of these tumors are reported to originate ${ }^{[9]}$. Collectively, these observations raise the potential for the presence of a potential hybrid transition state, in which reprogrammed enteric neural crestderived cells escape a mature neuroglial lineage and acquire a neuroendocrine phenotype.

In identifying molecular features unique to the tumor-naïve hyperplastic antrum, we focused on a subset of genes enriched in our study and previously reported to be upregulated in human duodenal gastrinomas (DGASTs), including Hapl, Mn1, and Uchl1 ${ }^{[60]}$. Among these, the neuronal protein Huntingtin-associated protein (Hap1) is also expressed by enteroendocrine cells (EECs) within the GI tract and was recently reported to be expressed in G cells but not in other EEC lineages of the pyloric antrum ${ }^{[61]}$. This is consistent with our observation of increased Hapl gene expression and higher antral gastrin and Grp expression levels. In addition, GFAP ${ }^{\triangle M e n l}$ mice exhibited increased expression of Meningioma $1(\mathrm{Mn} 1)$, a non-glial neural progenitor marker that is strongly associated with primitive neural ectodermal tumors of neural crest cell origin ${ }^{[62]}$. Similarly, Ubiquitin C-Terminal Hydrolase L1 (Uchl1) is a pan-neuronal marker that is also expressed by neural progenitor cells of the enteric nervous system and by neuroendocrine cells ${ }^{[63-}$ $65]$. 
Taken together, enrichment of these neural lineage-specific genes in both the hyperplastic antra of GFAP $\triangle$ Men1 mice and human DGASTs arising from the Brunner's glands suggests concordance between the human Brunner's glands and the pyloric antrum. A recent study showed that transplanted human antral organoids co-cultured with human ENCCs induced the formation of highly differentiated epithelium analogous to the Brunner's glands ${ }^{[66]}$. Subsequent analysis of ENCCs identified elevated expression of the Shh-induced posteriorizing factors Bmp4 and Bmp7, and inhibition of these factors in ENCCs attenuated Brunner's gland formation in organoid cocultures ${ }^{[61]}$. Consistent with our observations, ENCCs and their progeny carry the potential to direct epithelial differentiation in favor of an endocrine phenotype, and these events are strongly influenced by Shh-mediated signaling. Importantly, our observations prompt further investigation into both neuroglial cell autonomous and non-cell autonomous mechanisms presaging these outcomes.

In summary, we report the development of a glial-directed mouse model of human MEN1 syndrome with the aim of defining the contribution of neural crest cell reprogramming in neuroendocrine cell differentiation and tumorigenesis. By addressing a previously uncharacterized compartment of GEP-NETs, this study carries the potential to identify a unique cell-of-origin for these neoplasms. The importance of these discoveries is emphasized by the fact that GEP-NETs comprise remarkably diverse neoplasms that vary in location, mutational profile, and response to therapy. Such heterogeneity may in part be explained by divergent cellular origins for NETs as a function of different tissue sites. Previous work centered on mapping their unique transcriptional signatures suggests the potential for neuroglial reprogramming in the development of human DGASTs. Defining the cell-of-origin and the events preceding neoplastic transformation will be critical to informing molecular signaling pathways that can then be targeted therapeutically. 


\section{MATERIALS AND METHODS}

All authors had access to the study data and had reviewed and approved the final manuscript.

\section{Animal Studies}

All animal studies received approval by the University of Arizona Institutional Animal Care and Use Committee and conform to the Animal Research: Reporting of In Vivo Experiments guidelines. GFAP-Cre transgenic mice on a C57BL/6J genetic background were purchased from Jackson Laboratories and bred onto a $M e n 1^{F L / F L}$ background $\left(G F A P^{\triangle M e n l}\right)$ to conditionally delete Men1 in GFAP-expressing cells. A subset of wild type and $G F A P^{\triangle M e n 1}$ mice were bred onto a somatostatin-null background $\left(S s t^{-/}\right) . G F A P^{\triangle M e n 1} ; S s t^{-/}$mice were further bred onto a $K i f 3 a^{F L / F L}$ background to conditionally delete Kif3a under the control of the Gfap promoter $\left(G F A P^{\Delta M e n 1 ; \Delta K i f 3 a} ; S s t^{t^{-}}\right)$. Wild type, GFAP ${ }^{\Delta M e n 1}, G F A P^{\Delta M e n l} ; S s t^{-/-}$, and $G F A P^{\Delta M e n 1 ; \Delta K i f 3 a} ; S s t^{-/-}$mice were also bred to mice carrying a lox-Stop-lox-tdTomato sequence to selectively express the tdTomato fluorescent reporter in $\mathrm{GFAP}^{+}$cells. Mice were necropsied at 8-9 months of age and between 13-24 months of age. All histological characterization and downstream comparisons were made using littermate controls.

\section{Cell and Tissue Culture}

Primary tumor neurospheres were generated from an 18 mo-old female GFAP ${ }^{\triangle M e n l}$ mouse presenting with a large pituitary prolactinoma. A four-by-two millimeter piece of tissue was cut from the tumor and minced into $1 \mathrm{~mm}$ pieces on ice. The tissue was transferred to a $10 \mathrm{~mL}$ solution of Dispase/DNase solution warmed to $37^{\circ} \mathrm{C}(0.1 \%$ dispase, $0.01 \%$ DNase, $10 \mathrm{mM}$ HEPES, DPBS without calcium and magnesium) and incubated in a shaking water bath $(60 \mathrm{rpm})$ at $37^{\circ} \mathrm{C}$ for 80 minutes. Half-way through the incubation, the tissue was shaken manually three times to facilitate 
dissociation. The tissue was triturated 10 times with a $10 \mathrm{~mL}$ serological pipette, then filtered through a $40 \mu \mathrm{m}$ cell strainer before centrifuging at $123 \mathrm{x}$ g for $10 \mathrm{~min}$ at $4^{\circ} \mathrm{C}$. The cell pellet was resuspended in Neurosphere Media consisting of DMEM/F12 (ThermoFisher, Waltham, MA), 1X GlutaMAX (Invitrogen, Carlsbad, CA), 1X N2 (Gibco, Waltham, MA), 1X B-27 (Gibco), 100U Penicillin-streptomycin (Invitrogen), $10 \mathrm{mM} \mathrm{HEPES} \mathrm{(Invitrogen),} 30 \mathrm{ng} / \mathrm{mL}$ mouse recombinant FGF-10 (Biolegend, San Diego, CA), and 30 ng/mL recombinant human EGF (R\&D Systems, Minneapolis, MN). Cells were plated in a non-tissue culture treated 6-well plate and incubated overnight at $37^{\circ} \mathrm{C}$. Media was changed every 2-3 days by collecting neurospheres, centrifuging, and reseeding the pellet in fresh medium.

A rat enteric glial cell line was purchased from ATCC (\#CRL-2690) and grown in DMEM supplemented with 10\% Fetal Bovine Serum (FBS) and 100U Penicillin-streptomycin (EGC/PK060399egfr, ATCC, Manassas, VA). Upon reaching 30-50\% confluency, glial cells were switched to 5\% FBS-containing media and used for small interfering RNA (siRNA) experiments. Both the non-targeting siRNA and Men1 siRNA consisted of a SMARTpool of four ONTARGETplus siRNA constructs (\#L-090784-02-0005 for Men1 pool and \#D-001810-10-05 for Non-targeting pool, Dharmacon Horizon Discovery, Lafayette, CO). Cells were transfected with 25 nM siRNA using Lipofectamine 3000 without p3000 reagent according to manufacturer instructions (ThermoFisher). Following 48 to $72 \mathrm{~h}$ post-transfection, cells were harvested for downstream RNA or protein extraction.

\section{Immunohistochemistry and Immunofluorescent Staining}

Mouse tissues were fixed overnight at $4^{\circ} \mathrm{C}$ in $4 \%$ paraformaldehyde. Tissues were paraffinembedded, cut into $5 \mu \mathrm{m}$ sections and placed on frosted glass slides. Slides were deparaffinized in 
three xylene washes, then rehydrated in $100 \%, 90 \%$, and $70 \%$ ethanol washes. Slides were washed in TBS with $0.05 \%$ Tween-20 (TBST) before proceeding with antigen retrieval. Slides were boiled in $1 \mathrm{X}$ sodium citrate buffer $\mathrm{pH} 6.0$ for $30 \mathrm{~min}$ and allowed to cool to room temperature (RT) for 20 min prior to washing with TBST. Slides were incubated for $1 \mathrm{~h}$ at RT in blocking buffer consisting of 10\% donkey serum, 1\% Bovine Serum Albumin (BSA), 0.1\% Triton X-100 in TBST. In some instances, tissues were permeabilized with $0.5 \%$ Triton $\mathrm{X}-100$ for $5 \mathrm{~min}$ at $\mathrm{RT}$ prior to blocking. Tissues were incubated in primary antibody overnight at $4^{\circ} \mathrm{C}$. Primary antibodies were prepared in blocking solution according to the dilutions listed in STAR Methods Table 1. Following overnight incubation, slides were washes in TBST and incubated in Alexa Fluorconjugated secondary antibodies (Molecular Probes, Eugene, OR; Invitrogen) diluted 1:500 in 1\% BSA and TBST for $1 \mathrm{~h}$ at RT in the dark. Slides were washed in TBS before mounting with \#1.5 coverslips using Prolong Gold anti-fade mounting medium with DAPI (Life Technologies, Rockville, MD). Immunofluorescence was visualized using the Olympus BX53F epifluorescence microscope (Center Valley, PA).

For immunofluorescent staining of tumor neurospheres, neurospheres were collected and centrifuged. The pellet was resuspended in 3.7\% paraformaldehyde and transferred to a 24 -well $0.17 \mathrm{~mm}$ glass bottom plate. Neurospheres were fixed for $15 \mathrm{~min}$ at RT, then washed with $1 \mathrm{X}$ TBST. Neurospheres were permeabilized with $0.5 \%$ triton $\mathrm{X}-100$ for $5 \mathrm{~min}$ at RT, washed, then blocked in $20 \%$ donkey serum, $1 \%$ BSA and $0.1 \%$ triton in TBST for 30 min at RT. Primary antibodies were diluted in 5\% donkey serum 1\% BSA, $0.1 \%$ triton in TBST and added to wells for overnight incubation at $4^{\circ} \mathrm{C}$. Primary antibodies and dilutions are listed in Methods Table 1 . Neurospheres were washed thoroughly with TBST and incubated for $1 \mathrm{~h}$ at RT in Alexa Fluorconjugated secondary antibodies diluted 1:500 in 1\% BSA and TBST. Neurospheres were washed 
with TBS, then stored in TBS containing Prolong gold antifade mounting medium with DAPI. Samples were imaged using a Nikon Ti2-E inverted microscope with a Crest X-Light V2 L-FOV Spinning Disk Confocal and a Photometrics Prime 95B-25MM Back-illuminated sCMOS Camera (Nikon, Tokyo, Japan).

Mouse tissues with endogenous tdTomato reporter expression were fixed in $4 \%$ paraformaldehyde for $1 \mathrm{~h}$ on ice before dehydrating overnight at $4{ }^{\circ} \mathrm{C}$ in a solution of $30 \%$ sucrose-

PBS. Tissues were then embedded in Tissue-Tek Optimal Cutting Temperature (OCT) compound (Sakura Finetek, Torrance, CA) and frozen on dry ice. OCT blocks were cryosectioned to a $10 \mu \mathrm{m}$ thickness and melted onto frosted glass slides prior to mounting with Prolong Gold anti-fade mounting medium containing DAPI. TdTomato signal was visualized using the Olympus BX53F epifluorescence microscope. Images drawing comparisons between groups were acquired with identical laser acquisition settings (Center Valley, PA).

\section{Quantitative PCR}

RNA was extracted from frozen mouse tissues using the Purelink RNA Extraction Kit (Invitrogen). Tissues were homogenized with a rotor-stator homogenizer in RNA lysis buffer containing $1 \% \beta$-mercaptoethanol and RNA was isolated following manufacturer's instructions. Extracted RNA was treated with ezDNase to remove any residual genomic DNA and then prepared for cDNA synthesis using Superscript VILO IV Master Mix according to manufacturer's instructions (Invitrogen). Quantitative real-time PCR was performed using PowerUp SYBR Green Master Mix (Invitrogen) with 20 ng cDNA added to each reaction. Predesigned forward and reverse primer sets were purchased from Integrated DNA Technologies (IDT, Coralville, IA) and used at a final $500 \mathrm{nM}$ concentration. Quantitative PCR was performed using the QuantStudio 3 
Real-Time PCR System (Applied Biosystems, Waltham, MA) with the following cycling conditions: $2 \mathrm{~min}$ at $50^{\circ} \mathrm{C}, 2 \mathrm{~min}$ at $95^{\circ} \mathrm{C}$, denaturing step for $1 \mathrm{sec}$ at $95^{\circ} \mathrm{C}$, extension and annealing for $1 \mathrm{~min}$ at $60^{\circ} \mathrm{C}$, followed by a dissociation melt curve stage to confirm primer specificity. All forward and reverse primers were purchased as validated predesigned PrimeTime qPCR Assay primer sets used for SYBR ${ }^{\circledR}$ Green dye (Integrated DNA Technologies, Coralville, IA).

\section{Ex vivo Fluorescence Imaging}

At 8-9 mos of age, GFAP Cre-tdTomato mice were euthanized following overnight fasting and the stomach and proximal duodenum were collected for ex vivo imaging prior to fixation for OCT embedding. The stomach and proximal duodenum were opened along the greater curvature and contents were flushed with cold PBS. Both tissues were placed in cold PBS with mucosa facing up and imaged in a dark room using a wide field fluorescence imaging system. Illumination was provided by a 300W xenon arc lamp source (LS-OF30, Sutter instruments, Novato CA). Illumination light was filtered with a $554 \mathrm{~nm}$ excitation filter with $23 \mathrm{~nm}$ bandwidth (FF01-554/2325, Semrock Inc., Rochester NY) and delivered using a fiber bundle (LLG, Sutter Instruments). Images were collected with a 1/2" CCD Monochrome Camera (EO-1312M, Edmund Optics, Barrington NJ) with a $35 \mathrm{~mm}$ fixed focal length lens (\#59-872, Edmund Optics) and a $594 \mathrm{~nm}$ long-pass filter (BLP01-594R-25, Semrock) mounted on a rigid arm above the sample plane. Images were collected with an exposure time of $60 \mathrm{~ms}$ and saved in 16 bit .tif format. Each day, a flat-field image was collected by imaging a white diffuse reflectance target (\#58-609, Edmund Optics) to correct for spatial non-uniformity using unfiltered illumination. Additionally, a power measurement was collected for the filtered illumination light at the sample plane using a power 
meter (S120C, Thorlabs, Newton NJ) to adjust for day-to-day variations of light source intensity. The collected images were first normalized through division by the flat-field image and the light source power measured on the day of sample acquisition. Regions of interest were then manually drawn around the forestomach, corpus, antrum and duodenum using ImageJ. Fluorescence intensity was calculated in the region of interest and averaged over the number of valid pixels. Any pixels with $5 \%$ of saturation (e.g., digital value of 65535) were discarded from the analysis.

\section{RNA Sequencing}

RNA was extracted from three $G F A P^{\triangle M e n 1}$ PNETs, pitNETs, and the pyloric antrum using the Purelink RNA Extraction kit as previously described (Invitrogen). Pancreas, pituitary, and antra of age-matched wild type mice were used as controls. Due to its small size, three normal pituitaries were pooled for each sample, and a total of three samples were submitted for sequencing (i.e. nine wild type pituitaries total). RNA was processed on the bioanalyzer for quality control prior to proceeding with mRNA library construction and bulk RNA sequencing. Due to degradation of pancreas tissues by pancreatic enzymes, only antral extracts and pituitary samples were usable for downstream library construction and sequencing. Samples were sequenced by Novogene using Ilumina sequencing platforms and the resulting calculated Fragments Per Kilobase of transcript sequence per Millions base pairs sequenced (FPKM) values were analyzed for differential gene expression, Principal Component Analysis, and Gene Ontology (GO) Enrichment Analysis. Differential expression between wild type and $G F A P^{\Delta M e n 1}$ groups was determined using the DESeq2 R package (1.20.0) using a negative binomial distribution model. $P$ values were adjusted for multiple testing using the Benjamini and Hochberg's method for controlling false discovery rate and genes with adjusted $p$ value $<0.05$ were considered 
significantly differentially expressed. The statistical enrichment of DEGs in KEGG pathways was tested using the clusterProfiler R package with correction for gene length bias. GO terms with a corrected $p$ value $<0.05$ were considered significantly enriched. Heatmaps of significant DEGs assigned to specific signatures of interest were generated using Python 3 using the open-source packages Seaborn and Pandas. For each gene, the Z-score was calculated and plotted as a function of color, with the color white being fixed to a Z-score of 0 .

\section{Western Blot Analysis}

Seventy-two hours following siRNA-mediated Men1 silencing, rat enteric glial cells were harvested by washing twice in cold DPBS and lysing in cold RIPA buffer containing phosphatase and protease inhibitors. Cells were collected by scraping, then homogenized by passing through a 20G needle syringe five times. The resulting lysate was centrifuged at 15,000 x g for $20 \mathrm{~min}$ at $4^{\circ} \mathrm{C}$. The supernatant was collected and used for western blot analysis as follows. Lysates were prepared in reducing conditions in 1 X SDS buffer with 5\% $\beta$-mercaptoethanol and denatured by boiling at $95^{\circ} \mathrm{C}$ for $5 \mathrm{~min} .15 \mu \mathrm{g}$ of protein was loaded into a NuPage 4-12\% Bis-Tris Mini Protein Gel and allowed to migrate for $1 \mathrm{~h}$ at $140 \mathrm{~V}$ in $1 \mathrm{X}$ MOPS Gel Electrophoresis Buffer. Proteins were transferred onto a pre-wetted PVDF membrane using the iBlot2 transfer system (P0 setting, $7 \mathrm{~min}$ ), then blocked in 5\% BSA TBST for $1 \mathrm{~h}$ at RT. Membranes were incubated overnight at $4^{\circ} \mathrm{C}$ in primary antibody diluted in blocking buffer at the dilutions listed in STAR Methods Table 1. Membranes were washed in TBST, then incubated for $1 \mathrm{~h}$ at RT in a corresponding host IgG HRPconjugated secondary antibody diluted 1:3000 in blocking buffer. Membranes were washed again in TBST and incubated in Pierce ECL reagent (ThermoFisher) for $1 \mathrm{~min}$ prior to developing on film in a dark room. 
For analysis of tissue extracts, gastric antra of 8-9 mo-old mice were homogenized in icecold RIPA buffer using a rotor-stator homogenizer. Samples were centrifuged at 15,000 x g for 15 min and the supernatant $(20 \mu \mathrm{g})$ was evaluated for Gli2 protein expression (STAR Methods Table $1)$.

\section{Co-Immunoprecipitation Assay}

Co-immunoprecipitation of menin and GFAP was performed in rat enteric glial cells. Prior to lysis, cells were collected in ice-cold DPBS, centrifuged, and washed once with cold DPBS. The cell pellet was resuspended in either RIPA buffer or cytoplasmic lysis buffer to generate a whole cell lysate and cytoplasmic extract, respectively. Buffers were supplemented with 1X HALT protease and phosphatase inhibitor. Whole cell lysates were prepared by passing through a 20G syringe $10 \mathrm{X}$ and centrifuging at $15,000 \mathrm{x}$ g for $15 \mathrm{~min}$ at $4^{\circ} \mathrm{C}$. Cytoplasmic extracts were pipetted up and down $20 \mathrm{X}$, incubated on ice for $10 \mathrm{~min}$, then vortexed for $15 \mathrm{sec}$ prior to centrifuging at $15,000 \mathrm{x}$ g for $5 \mathrm{~min}$ at $4^{\circ} \mathrm{C}$. The supernatant was saved as the cytoplasmic fraction. The remaining pellet containing nuclear protein was washed once in cytoplasmic lysis buffer then resuspended in nuclear lysis buffer (1:4 v/v nuclear to cytoplasmic buffer ratio). The extract was incubated on ice for $20 \mathrm{~min}$, vortexed vigorously, then centrifuged at $15,000 \mathrm{x} \mathrm{g}$ for $15 \mathrm{~min}$ at $4^{\circ} \mathrm{C}$ to remove chromatin. Protein concentration in freshly prepared lysates was evaluated by bicinchoninic assay. To form an antigen-antibody complex, 100-500 ug lysate was incubated with either Mouse antiMenin monoclonal antibody (Bethyl Laboratories, \#A500-003A, 1:100 v/v) or Rat anti-GFAP monoclonal antibody (Invitrogen, \#13-0300, 1:100 v/v) overnight at $4^{\circ} \mathrm{C} .50 \mu \mathrm{L}$ of prewashed Protein A/G agarose beads (Pierce, \#20423) was added to each antigen-antibody complex and incubated overnight at $4^{\circ} \mathrm{C}$ with gentle agitation. Bead-complexes were pelleted at 3,000 x g for 2 
min and washed three times with wash buffer. Bound proteins were eluted by mixing with 2X SDS loading buffer containing 5\% \% $\beta$-mercaptoethanol as a denaturing agent. Samples were incubated at $95^{\circ} \mathrm{C}$ for $10 \mathrm{~min}$, vortexed, then centrifuged to remove beads. The remaining protein suspension was evaluated by western blot as previously described. Extracts precipitated using Mouse antiMenin antibody were probed using Rabbit anti-GFAP antibody (Dako Agilent Technologies, \#Z033429, 1:2000) whereas extracts precipitated with Rat anti-GFAP antibody were probed with Rabbit anti-Menin antibody (Bethyl Laboratories, \#A300-105A 1:10000).

\section{Gastrin Enzyme Immunoassay}

Gastrin peptide was extracted from the antra of 8-9 mo-old mice by boiling tissues in 200 $\mu \mathrm{L}$ of nuclease-free water and vigorously vortexing. The resulting solution was centrifuged to pellet debris and $50 \mu \mathrm{L}$ of the supernatant was used for the Gastrin Enzyme Immunoassay according to manufacturer's instructions (Sigma, \#RAB0200).

\section{Statistical Analysis}

Assays comparing two genotypes or groups were evaluated for statistical significance by applying unpaired Student's t-test. All quantitative PCR data expressed as fold-change (2-ddCt) were $\log$ transformed to fit a normal distribution prior to performing statistical analysis. Comparisons consisting of three or more genotypes or groups were evaluated for significance using One-way Analysis of Variance (ANOVA), with Tukey post-test. Significance was determined as $* p<0.05, * * p<0.01, * * * p<0.001, * * * * p<0.0001$ using Graphpad Prism (v9) software. 
Methods Table 1. List of primary antibodies and dilutions

\begin{tabular}{|l|l|l|l|}
\hline Primary Antibodies & Vendor & Catalog \# & Dilution/Application \\
\hline Menin (Rabbit pAb) & Bethyl Laboratories & A300-105A & $\begin{array}{l}1: 2,000 \text { (IHC/IF with TSA) } \\
1: 10,000(\mathrm{WB})\end{array}$ \\
\hline Chromogranin A & Abcam & 15160 & $1: 100$ (IHC/IF) \\
\hline Synaptophysin & Cell Signaling Technologies & 9020 & $1: 200$ (IHC/IF) \\
\hline Irx-2 & Abcam & 196755 & $1: 100$ (IHC/IF) \\
\hline Ki-67 & Cell Signaling Technologies & 9449 & $1: 400$ (IHC/IF) \\
\hline$\alpha$-smooth muscle actin & Abcam & 5694 & $1: 200$ (IHC/IF) \\
\hline Glucagon & Cell Signaling Technologies & 2760 & $1: 100$ (IHC/IF) \\
\hline Insulin & Cell Signaling Technologies & 3012 & $1: 1000$ (IHC/IF) \\
\hline GFAP (Rabbit pAb) & Dako Agilent Technologies & Z033429 & $1: 400$ (IHC/IF) \\
& & & $1: 2,000$ (WB) \\
\hline GFAP & Invitrogen & PA1-10004 & $1: 400$ (IHC/IF) \\
\hline Nestin & Novus Biologicals & NB100-1604 & $1: 500$ (IHC/IF) \\
& & & $1: 100$ (ICC/IF) \\
\hline Sox2 & Novus Biologicals & NB110-37235 & $1: 200$ (ICC/IF) \\
\hline Pit-1 & Novus Biologicals & NBP1-92273 & $1: 500$ (IHC/IF) \\
\hline Prolactin & Abcam & 183967 & $1: 200$ (IHC/ICC/IF) \\
\hline Gastrin & Dako Agilent Technologies & A0568 & $1: 1000$ (IHC/IF) \\
\hline Acetylated-tubulin & Sigma & MABT868 & $1: 200$ (IHC/IF) \\
\hline Gastrin-releasing peptide & Invitrogen & PA5-115272 & $1: 200$ (IHC/IF) \\
\hline GAPDH & Cell Signaling Technologies & $5174 S$ & $1: 2,000$ (WB) \\
\hline Gli2 & Santa Cruz Technologies & 271786 & $1: 1,000$ (WB) \\
\hline Menin (Mouse mAb) & Bethyl Laboratories & A500-003A & $1: 100$ (IP) \\
\hline GFAP (Rat mAb) & Invitrogen & $13-0300$ & $1: 100$ (IP) \\
\hline & & &
\end{tabular}




\section{REFERENCES}

1. Dasari A, Shen C, Halperin D, et al. Trends in the Incidence, Prevalence, and Survival Outcomes in Patients With Neuroendocrine Tumors in the United States. JAMA Oncol. 2017;3(10):1335-1342. doi:10.1001/jamaoncol.2017.0589

2. Lee MR, Harris C, Baeg KJ, Aronson A, Wisnivesky JP, Kim MK: Incidence Trends of Gastroenteropancreatic Neuroendocrine Tumors in the United States. Clin Gastroenterol Hepatol 2019, 17(11):2212-2217 e2211.

3. Schimmack S, Svejda B, Lawrence B, Kidd M, Modlin IM: The diversity and commonalities of gastroenteropancreatic neuroendocrine tumors. Langenbecks Arch Surg 2011, 396(3):273-298.

4. Thakker RV. Multiple endocrine neoplasia type 1 (MEN1). Best Pract Res Clin Endocrinol Metab. 2010;24(3):355-370. doi:10.1016/j.beem.2010.07.003

5. Thakker RV, Newey PJ, Walls GV, et al. Clinical practice guidelines for multiple endocrine neoplasia type 1 (MEN1). J Clin Endocrinol Metab. 2012;97(9):2990-3011. doi:10.1210/jc.2012-1230

6. Waldum HL, Sandvik AK, Syversen U, Brenna E. The enterochromaffin-like (ECL) cell. Physiological and pathophysiological role. Acta Oncol. 1993;32(2):141-147. doi:10.3109/02841869309083903

7. Chao C, Hellmich MR. Gastrin, inflammation, and carcinogenesis. Curr Opin Endocrinol Diabetes Obes. 2010;17(1):33-39. doi:10.1097/MED.0b013e328333faf8

8. Jain RN, Samuelson LC. Differentiation of the gastric mucosa. II. Role of gastrin in gastric epithelial cell proliferation and maturation. Am J Physiol Gastrointest Liver Physiol. 2006;291(5):G762-G765. doi:10.1152/ajpgi.00172.2006

9. Duan S, Rico K, Merchant JL. Gastrin: From Physiology to Gastrointestinal Malignancies, Function. 2021;3(1):zqab062, https://doi.org/10.1093/function/zqab062

10. Anlauf M, Perren A, Meyer CL, et al. Precursor lesions in patients with multiple endocrine neoplasia type 1-associated duodenal gastrinomas. Gastroenterology. 2005;128(5):11871198. doi:10.1053/j.gastro.2005.01.058

11. Vanoli A, La Rosa S, Klersy C, et al. Four Neuroendocrine Tumor Types and Neuroendocrine Carcinoma of the Duodenum: Analysis of 203 Cases. Neuroendocrinology. 2017;104(2):112-125. doi:10.1159/000444803

12. Crabtree JS, Scacheri PC, Ward JM, et al. A mouse model of multiple endocrine neoplasia, type 1, develops multiple endocrine tumors. Proc Natl Acad Sci U S A. 2001;98(3):11181123. doi:10.1073/pnas.98.3.1118

13. Sundaresan S, Kang AJ, Hayes MM, Choi EK, Merchant JL. Deletion of Men 1 and somatostatin induces hypergastrinemia and gastric carcinoids [published correction appears in Gut. 2017 Nov;66(11):2012]. Gut. 2017;66(6):1012-1021. doi:10.1136/gutjnl-2015-310928 
14. Sundaresan S, Meininger CA, Kang AJ, et al. Gastrin Induces Nuclear Export and Proteasome Degradation of Menin in Enteric Glial Cells. Gastroenterology. 2017;153(6):1555-1567.e15. doi:10.1053/j.gastro.2017.08.038

15. Furlan A, Dyachuk V, Kastriti ME, et al. Multipotent peripheral glial cells generate neuroendocrine cells of the adrenal medulla. Science. 2017;357(6346):eaal3753. doi:10.1126/science.aal3753

16. Fielitz K, Althoff K, De Preter K, et al. Characterization of pancreatic glucagon-producing tumors and pituitary gland tumors in transgenic mice overexpressing MYCN in hGFAPpositive cells. Oncotarget. 2016;7(46):74415-74426. doi:10.18632/oncotarget.12766

17. Tang LH, Untch BR, Reidy DL, et al. Well-Differentiated Neuroendocrine Tumors with a Morphologically Apparent High-Grade Component: A Pathway Distinct from Poorly Differentiated Neuroendocrine Carcinomas. Clin Cancer Res. 2016;22(4):1011-1017. doi:10.1158/1078-0432.CCR-15-0548

18. Regoli M, Orazioli D, Gerli R, Bertelli E. Glial fibrillary acidic protein (GFAP)-like immunoreactivity in rat endocrine pancreas. J Histochem Cytochem. 2000;48(2):259-266. doi:10.1177/002215540004800211

19. Middeldorp J, Hol EM. GFAP in health and disease. Prog Neurobiol. 2011;93(3):421-443. doi:10.1016/j.pneurobio.2011.01.005

20. van den Berge SA, Middeldorp J, Zhang CE, et al. Longterm quiescent cells in the aged human subventricular neurogenic system specifically express GFAP-delta. Aging Cell. 2010;9(3):313-326. doi:10.1111/j.1474-9726.2010.00556.x

21. Liu Y, Namba T, Liu J, Suzuki R, Shioda S, Seki T. Glial fibrillary acidic proteinexpressing neural progenitors give rise to immature neurons via early intermediate progenitors expressing both glial fibrillary acidic protein and neuronal markers in the adult hippocampus. Neuroscience.2010;166(1):241-251.

doi:10.1016/j.neuroscience.2009.12.026

22. Raponi E, Agenes F, Delphin C, et al. S100B expression defines a state in which GFAPexpressing cells lose their neural stem cell potential and acquire a more mature developmental stage. Glia. 2007;55(2):165-177. doi:10.1002/glia.20445

23. Lopez-Egido J, Cunningham J, Berg M, Oberg K, Bongcam-Rudloff E, Gobl A. Menin's interaction with glial fibrillary acidic protein and vimentin suggests a role for the intermediate filament network in regulating menin activity. Exp Cell Res. 2002;278(2):175-183. doi:10.1006/excr.2002.5575

24. Poisson A, Zablewska B, Gaudray P. Menin interacting proteins as clues toward the understanding of multiple endocrine neoplasia type 1. Cancer Lett. 2003;189(1):1-10. doi:10.1016/s0304-3835(02)00509-8

25. van Bodegraven EJ, Sluijs JA, Tan AK, Robe PAJT, Hol EM. New GFAP splice isoform $(\mathrm{GFAP} \mu)$ differentially expressed in glioma translates into $21 \mathrm{kDa} \mathrm{N}$-terminal GFAP protein. FASEB J. 2021;35(3):e21389. doi:10.1096/fj.202001767R 
26. van Bodegraven EJ, van Asperen JV, Sluijs JA, et al. GFAP alternative splicing regulates glioma cell-ECM interaction in a DUSP4-dependent manner. FASEB J. 2019;33(11):12941-12959. doi:10.1096/fj.201900916R

27. Danielyan L, Tolstonog G, Traub P, et al. Colocalization of glial fibrillary acidic protein, metallothionein, and MHC II in human, rat, NOD/SCID, and nude mouse skin keratinocytes and fibroblasts. $J$ Invest Dermatol. 2007;127(3):555-563. doi:10.1038/sj.jid.5700575

28. Wuescher L, Angevine K, Hinds T, Ramakrishnan S, Najjar SM, Mensah-Osman EJ. Insulin regulates menin expression, cytoplasmic localization, and interaction with FOXO1.Am $J$ Physiol Endocrinol Metab. 2011;301(3):E474-E483. doi:10.1152/ajpendo.00022.2011

29. Cao Y, Liu R, Jiang X, et al. Nuclear-cytoplasmic shuttling of menin regulates nuclear translocation of \{beta\}-catenin. Mol Cell Biol. 2009;29(20):5477-5487. doi:10.1128/MCB.00335-09

30. Costa M, Furness JB, Yanaihara N, Yanaihara C, Moody TW. Distribution and projections of neurons with immunoreactivity for both gastrin-releasing peptide and bombesin in the guinea-pig small intestine. Cell Tissue Res. 1984;235(2):285-293. doi:10.1007/BF00217852

31. Dutton R, Yamada T, Turnley A, Bartlett PF, Murphy M. Sonic hedgehog promotes neuronal differentiation of murine spinal cord precursors and collaborates with neurotrophin 3 to induce Islet-1.J Neurosci. 1999;19(7):2601-2608. doi:10.1523/JNEUROSCI.19-07-02601.1999

32. Villavicencio EH, Walterhouse DO, Iannaccone PM. The sonic hedgehog-patched-gli pathway in human development and disease. Am J Hum Genet. 2000;67(5):1047-1054. doi:10.1016/S0002-9297(07)62934-6

33. Ding L, Sontz EA, Saqui-Salces M, Merchant JL. Interleukin-1 $\beta$ Suppresses Gastrin via Primary Cilia and Induces Antral Hyperplasia. Cell Mol Gastroenterol Hepatol. 2021;11(5):1251-1266. doi:10.1016/j.jcmgh.2020.12.008

34. Priestley P, Baber J, Lolkema MP, et al. Pan-cancer whole-genome analyses of metastatic solid tumours. Nature. 2019;575(7781):210-216. doi:10.1038/s41586-019-1689-y

35. Shen HC, He M, Powell A, et al. Recapitulation of pancreatic neuroendocrine tumors in human multiple endocrine neoplasia type I syndrome via Pdx1-directed inactivation of Men1. Cancer Res. 2009;69(5):1858-1866. doi:10.1158/0008-5472.CAN-08-3662

36. Shen HC, Ylaya K, Pechhold K, et al. Multiple endocrine neoplasia type 1 deletion in pancreatic alpha-cells leads to development of insulinomas in mice. Endocrinology. 2010;151(8):4024-4030. doi:10.1210/en.2009-1251

37. Wong C, Tang LH, Davidson C, et al. Two well-differentiated pancreatic neuroendocrine tumor mouse models. Cell Death Differ. 2020;27(1):269-283. doi:10.1038/s41418-0190355-0 
38. Lines KE, Vas Nunes RP, Frost M, Yates CJ, Stevenson M, Thakker RV. A MEN1 pancreatic neuroendocrine tumour mouse model under temporal control. Endocr Connect. 2017;6(4):232-242. doi:10.1530/EC-17-0040

39. Harding B, Lemos MC, Reed AA, et al. Multiple endocrine neoplasia type 1 knockout mice develop parathyroid, pancreatic, pituitary and adrenal tumours with hypercalcaemia, hypophosphataemia and hypercorticosteronaemia. Endocr Relat Cancer. 2009;16(4):1313-1327. doi:10.1677/ERC-09-0082

40. Molofsky AV, Glasgow SM, Chaboub LS, et al. Expression profiling of Aldh111precursors in the developing spinal cord reveals glial lineage-specific genes and direct Sox9-Nfe211 interactions. Glia. 2013;61(9):1518-1532. doi:10.1002/glia.22538

41. Kaczmarczyk L, Reichenbach N, Blank N, et al. Slc1a3-2A-CreERT2 mice reveal unique features of Bergmann glia and augment a growing collection of Cre drivers and effectors in the 129S4 genetic background. Sci Rep. 2021;11(1):5412. Published 2021 Mar 8. doi:10.1038/s41598-021-84887-2

42. Tiwari N, Pataskar A, Péron S, et al. Stage-Specific Transcription Factors Drive Astrogliogenesis by Remodeling Gene Regulatory Landscapes. Cell Stem Cell. 2018;23(4):557-571.e8. doi:10.1016/j.stem.2018.09.008

43. Weng Q, Wang J, Wang J, et al. Single-Cell Transcriptomics Uncovers Glial Progenitor Diversity and Cell Fate Determinants during Development and Gliomagenesis. Cell Stem Cell. 2019;24(5):707-723.e8. doi:10.1016/j.stem.2019.03.006

44. Chen KS, Bridges CR, Lynton Z, et al. Transcription factors NFIA and NFIB induce cellular differentiation in high-grade astrocytoma. J Neurooncol. 2020;146(1):41-53. doi:10.1007/s11060-019-03352-3

45. Lam M, Sanosaka T, Lundin A, et al. Single-cell study of neural stem cells derived from human iPSCs reveals distinct progenitor populations with neurogenic and gliogenic potential. Genes Cells. 2019;24(12):836-847. doi:10.1111/gtc.12731

46. Bami M, Episkopou V, Gavalas A, Gouti M. Directed neural differentiation of mouse embryonic stem cells is a sensitive system for the identification of novel Hox gene effectors. PLoS One. 2011;6(5):e20197. doi:10.1371/journal.pone.0020197

47. Gouti M, Gavalas A. Hoxb1 controls cell fate specification and proliferative capacity of neural stem and progenitor cells. Stem Cells. 2008;26(8):1985-1997. doi:10.1634/stemcells.2008-0182

48. Gámez B, Rodriguez-Carballo E, Ventura F. BMP signaling in telencephalic neural cell specification and maturation. Front Cell Neurosci. 2013;7:87. Published 2013 Jun 4. doi:10.3389/fncel.2013.00087

49. Le Dréau G, Garcia-Campmany L, Rabadán MA, et al. Canonical BMP7 activity is required for the generation of discrete neuronal populations in the dorsal spinal cord. Development. 2012;139(2):259-268. doi:10.1242/dev.074948

50. Segklia A, Seuntjens E, Elkouris M, et al. Bmp7 regulates the survival, proliferation, and neurogenic properties of neural progenitor cells during corticogenesis in the mouse. PLoS One. 2012;7(3):e34088. doi:10.1371/journal.pone.0034088 
51. Voronova A, Fischer A, Ryan T, Al Madhoun A, Skerjanc IS. Ascl1/Mash1 is a novel target of Gli2 during Gli2-induced neurogenesis in P19 EC cells. PLoS One. 2011;6(4):e19174. Published 2011 Apr 29. doi:10.1371/journal.pone.0019174

52. Gurung B, Feng Z, Hua X. Menin directly represses Glil expression independent of canonical Hedgehog signaling. Mol Cancer Res. 2013;11(10):1215-1222. doi:10.1158/1541-7786.MCR-13-0170

53. Gurung B, Feng Z, Iwamoto DV, et al. Menin epigenetically represses Hedgehog signaling in MEN1 tumor syndrome. Cancer Res. 2013;73(8):2650-2658. doi:10.1158/00085472.CAN-12-3158

54. Boesmans W, Lasrado R, Vanden Berghe P, Pachnis V. Heterogeneity and phenotypic plasticity of glial cells in the mammalian enteric nervous system. Glia. 2015;63(2):229241. doi:10.1002/glia.22746

55. McCallum S, Obata Y, Fourli E, et al. Enteric glia as a source of neural progenitors in adult zebrafish. Elife. 2020;9:e56086. Published 2020 Aug 27. doi:10.7554/eLife.56086

56. Belkind-Gerson J, Graham HK, Reynolds J, et al. Colitis promotes neuronal differentiation of Sox2+ and PLP1+ enteric cells. Sci Rep. 2017;7(1):2525. Published 2017 May 31. doi:10.1038/s41598-017-02890-y

57. Veríssimo CP, Carvalho JDS, da Silva FJM, Campanati L, Moura-Neto V, Coelho-Aguiar JM. Laminin and Environmental Cues Act in the Inhibition of the Neuronal Differentiation of Enteric Glia in vitro. Front Neurosci. 2019;13:914. Published 2019 Sep 3. doi:10.3389/fnins.2019.00914

58. Joseph NM, He S, Quintana E, Kim YG, Núñez G, Morrison SJ. Enteric glia are multipotent in culture but primarily form glia in the adult rodent gut. $J$ Clin Invest. 2011;121(9):3398-3411. doi:10.1172/JCI58186

59. Barker N, van Es JH, Kuipers J, et al. Identification of stem cells in small intestine and colon by marker gene Lgr5. Nature. 2007;449(7165):1003-1007. doi:10.1038/nature06196

60. Rico K, Duan S, Pandey R, Chen Y, Chakrabarti J, Starr J, Zavros Y, Else T, Katona BW, Metz DC, Merchant, JL. Genome analysis identifies differences in the transcriptional targets of duodenal versus pancreatic neuroendocrine tumors. BMJ Open Gastroenterology. 2021;765. doi:10.1136/ bmjgast-2021-000765

61. Yanai A, Islam MN, Hayashi-Okada M, et al. Immunohistochemical relationships of huntingtin-associated protein 1 with enteroendocrine cells in the pyloric mucosa of the rat stomach. Acta Histochem. 2020;122(8):151650. doi:10.1016/j.acthis.2020.151650

62. Sturm D, Orr BA, Toprak UH, et al. New Brain Tumor Entities Emerge from Molecular Classification of CNS-PNETs. Cell. 2016;164(5):1060-1072. doi:10.1016/j.cell.2016.01.015

63. Sakurai M, Ayukawa K, Setsuie R, et al. Ubiquitin C-terminal hydrolase L1 regulates the morphology of neural progenitor cells and modulates their differentiation. $J$ Cell Sci. 2006;119(Pt 1):162-171. doi:10.1242/jcs.02716 
64. Wiese CB, Fleming N, Buehler DP, Southard-Smith EM. A Uchl1Histone2BmCherry:GFP-gpi BAC transgene for imaging neuronal progenitors. Genesis. 2013;51(12):852-861. doi:10.1002/dvg.22716

65. Shimada Y, Kudo Y, Maehara S, et al. Ubiquitin C-terminal hydrolase-L1 has prognostic relevance and is a therapeutic target for high-grade neuroendocrine lung cancers. Cancer Sci. 2020;111(2):610-620. doi:10.1111/cas.14284

66. Eicher AK, Kechele DO, Sundaram N, et al. Functional human gastrointestinal organoids can be engineered from three primary germ layers derived separately from pluripotent stem cells [published online ahead of print, 2021 Nov 23]. Cell Stem Cell. 2021;S19345909(21)00435-5. doi:10.1016/j.stem.2021.10.010 


\section{FIGURE LEGENDS}

Table 1. Summary of phenotypes observed in GFAP Cre; Men1 mice aged 13-24 months.

\section{Figure 1. GFAP-directed inactivation of Men1 promotes pancreatic islet hyperplasia and the} development of pancreatic neuroendocrine neoplasms. (A) H\&Es of well differentiated and poorly differentiated tumors in $G F A P^{\triangle M e n 1}$ mice compared to wild type (WT) and heterozygous groups. (B) and (C) H\&Es of well differentiated GFAP ${ }^{M e n 1}$ PNETs compared to (D) a poorly differentiated PNEC (E) Immunofluorescent staining of a PNET for chromogranin A and menin. Insets: tumor areas with absent and cytoplasmic menin (white). (F) Immunofluorescent staining of a PNET and (G) PNEC for synaptophysin and the alpha cell-specification factor Iriquois-2 (Irx2). Insets: Irx-2 is expressed in the nucleus of tumor cells (white). (H) and (I) Ki-67 and smooth muscle actin (SMA) staining of PNETs compared to (J) a PNEC. (K) H\&E of a GFAP $\triangle$ Menl PNET stained for (L) glucagon and (M) insulin. (N) Quantitation of neuroendocrine-related transcripts in WT pancreas and GFAP ${ }^{M e n l}$ PNETs. (O) Immunofluorescent staining of $G F A P{ }^{M e n l}$ PNETs for GFAP compared to normal islets and a poorly differentiated PNEC. (P) Quantitation of GFAP, $S 100 b$, and Men1 mRNA in WT pancreas and GFAP ${ }^{\triangle M e n 1}$ PNETs. $\mathrm{n}=4-5$ mice per group; * $p<$ $0.05, * * p<0.01$ by unpaired Student's T-test. Data are represented as mean $\pm \mathrm{SEM}$.

Figure 2. GFAP $\triangle M e n 1$ mice develop pituitary neuroendocrine tumors (pitNETs) that phenocopy human MEN1 prolactinomas. (A) and (B) H\&Es of a sagittal section of a $G F A P^{\triangle M e n I}$ pitNET. (C) Immunofluorescent staining of a $G F A P^{\triangle M e n 1}$ pitNET for synaptophysin and chromogranin A, (D) prolactin and (E) Ki-67 and Pit-1. (F) Immunofluorescent staining of a GFAP $\triangle M e n 1$ pitNET for GFAP and menin. (G) Tumors show low expression of menin and GFAP 
compared to the adjacent hypothalamus (Hyp). FV = fourth ventricle. (H) Quantitation of GFAP mRNA in WT pituitary and GFAP $\triangle M e n 1$ pitNETs. (I) Quantitation of neuroendocrine-related transcripts in WT pituitary and GFAP $4 M e n 1$ pitNETs. $\mathrm{n}=4-5$ mice per group with the exception of wild type pituitary group which represents four samples of three pooled pituitaries for a total of 12 tissues in this group; ${ }^{*} p<0.05, * * p<0.01, * * * p<0.001, * * * * p<0.0001$ by unpaired Student's T-test. Data are represented as mean \pm SEM. $(\mathrm{J})$ Brightfield images of cultured tumor neurospheres derived from a $G F A P^{\Delta M e n 1}$ pitNET showing growth at days (d) 2, 10, and 21. Tumor neurospheres were stained for prolactin (PRL) and the neural stem cell markers Nestin and Sox2. IgG and IgY secondary antibodies served as negative controls.

Figure 3. GFAP-directed deletion of Men1 stimulates hyperplastic reprogramming of the gastrointestinal epithelium and promotes neuroendocrine cell hyperplasia. (A) Representative low power H\&E stained images of WT and GFAP $\triangle M e n 1$ antrum and the proximal duodenal mucosa at 8-9 months of age. (B) Expression of chromogranin A mRNA in WT and GFAP $\triangle M e n 1$ corpus (CP), gastric antrum (AT) and duodenal mucosa (DUO). (C) Immunofluorescent staining of the corpus, antrum and duodenum for chromogranin A. (D) Synaptophysin mRNA expression in WT and GFAP $\triangle P^{\triangle M e n 1}$ corpus, gastric antrum and duodenal mucosa. (E) Immunofluorescent staining of the corpus, antrum and duodenum for synaptophysin. (F) Gastrin mRNA and (G) Immunofluorescent staining for gastrin in the corpus, antrum, and duodenum. $\mathrm{n}=6$ mice per group; $* p<0.05,{ }^{*} p<$ 0.01 by unpaired Student's T-test. Data are represented as mean $\pm \mathrm{SEM}$.

Figure 4. Conditional deletion of menin in $\mathrm{GFAP}^{+}$cells stimulates loss of a mature glial cell

phenotype. (A) Schematic of $G F A P^{\triangle M e n I}$-tdTomato construct. (B) Widefield images and (C) quantitation of tdTomato signal in the stomach and duodenum of wild type and GFAP ${ }^{\Delta e n l}$ mice 
expressing tdTomato reporter. $\mathrm{n}=4-5$ mice per group; $* * * p<0.001, * * * * p<0.0001$ by unpaired Student's T-test. (D) Whole tissue mounts of proximal duodenum from Cre negative and tdTomato-expressing mice showing tdTomato fluorescence localized to the myenteric plexus (MP). (E) Representative images of cryosections of corpus (CP), gastric antrum (AT), and proximal duodenum (DUO) from wild type and GFAP ${ }^{M e n 1}$ mice expressing tdTomato. (G) Coimmunoprecipitation (Co-IP) of menin and GFAP from rat EGC whole cell lysate (WCL), and nuclear $(\mathrm{N})$ and cytoplasmic (C) fractions followed by western blot for GFAP and menin, respectively. Input is 5-10\% of lysate used for IP. (H) Expression of Menl and the glial transcripts Gfap and S100b following siRNA-mediated Menl silencing in cultured rat enteric glial cells. $\mathrm{n}=3$ independent experiments; ${ }^{*} p<0.05, * * * p<0.001, * * * * p<0.0001$ by unpaired Student's t-test. Data are represented as mean \pm SEM. (I) Western blot of menin and GFAP in whole cell lysates following $72 \mathrm{~h}$ Men 1 silencing in rat enteric glial cells.

Figure 5. Transcriptome-wide analysis of gastric neuroendocrine hyperplasia and NENs identifies a role for glial-to-neural reprogramming in epithelial differentiation. (A) Volcano plot of significant DEGs in gastric antra of wild type and GFAP ${ }^{\triangle M e n 1}$ mice. (B) Volcano plot of significant DEGs in pooled wild type pituitaries and pitNETs of GFAP ${ }^{\Delta M^{2} n} 1$ mice. (C) Heatmaps of significant DEGs mapped to neuroendocrine differentiation in $G F A P^{\triangle M e n l}$ gastric antra and (D) pitNETs. (E) Heatmap of significant DEGs mapped to the neuroglial lineage in $G F A P{ }^{\triangle M e n 1}$ gastric antra and (F) pitNETs compared to litter-mate wild type controls. (G) KEGG Ontology Pathway analysis of gastric antra from wild type and $G F A P^{\triangle M e n l}$ mice showing the number of genes mapped to enriched pathways and their level of statistical significance. $(\mathrm{H})$ Immunofluorescent staining for 
gastrin-releasing peptide (Grp) and synaptophysin (Syp) in WT and GFAP ${ }^{M e n 1}$ gastric antra, shown as green and red respectively. Insets: colocalization of Grp and Syp in the gastric mucosa (yellow). (I) Quantitation of synaptophysin and Grp mRNA following 48h siRNA-mediated silencing of Men1 in rat enteric glial cells. $\mathrm{n}=3$ independent experiments; ${ }^{*} p<0.05$ and ${ }^{* *} p<$ 0.01 by unpaired Student's t-test. Data are represented as mean $\pm \mathrm{SEM}$.

Figure 6. Impairment of Sonic hedgehog (Shh) signaling in enteric glial cells attenuates neuroendocrine differentiation in $\boldsymbol{G F A P}{ }^{M e n 1}$ mice. (A) Schematic of $G F A P^{\triangle M e n 1 ; \Delta K i f 3 a}$;Sst ${ }^{-/-}$ mouse derivation. (B) Immunofluorescent staining for acetylated-tubulin and GFAP in the gastric antra of wild type and $G F A P^{\triangle M e n 1 ; \triangle K i f 3 a} ; S s t^{-/}$mice. Arrows indicate primary cilia marked by acetylated tubulin. (C) Western blot of Gli2 protein in gastric antral lysates of $\mathrm{Sst}^{-/}$(Con), GFAP $^{\Delta M e n 1} ; S s t^{-/}$, and GFAP ${ }^{\Delta M e n 1 ; \Delta K i f 3 a} ; S s t^{-/-}$mice. $\mathrm{n}=3$ mice. (D) Gli2 mRNA in gastric antra and duodenal mucosa of respective genotypes. $n=4-7$ mice per group. (E) Representative images of cryosections of corpus (CP), antrum (AT), and proximal duodenum (DUO) from wild type,

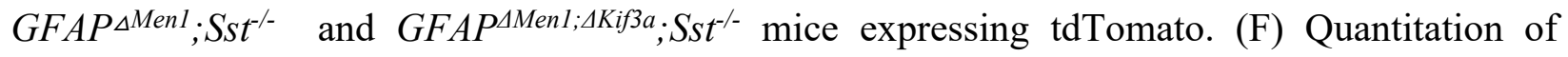
relative tdTomato fluorescence intensity following whole tissue ex vivo imaging. ${ }^{*} p<0.05,{ }^{*} p$ $<0.01$ by unpaired Student's T-test. (G) Quantitation of GFAP, (H) Chromogranin A, (I) Synaptophysin, and (J) Gastrin mRNA in the gastric antrum and duodenum of different groups. $\mathrm{n}=4-7$ mice per group; $* p<0.05, * * p<0.01, * * * p<0.001$ by unpaired Student's T-test. (K) Expression of antral gastrin peptide amongst the different genotypes. $\mathrm{n}=7-8$ mice per group; ${ }^{* *} p$ $<0.01, * * * p<0.001$. All data are represented as mean \pm SEM.

Supplementary Figure 1. (A) Principal Component Analysis plot capturing transcriptome-wide variation in three components. (B) Heatmaps of significant DEGs mapped to cell cycle regulation 
and (C) development in GFAP $\triangle M e n 1$ pitNETs. (D) Validation of select DEGs in pitNETs versus wild type pituitary by quantitative PCR. $\mathrm{n}=4-5$ mice per group. $* p<0.05, * * * p<0.001$ by Twoway ANOVA. Data are represented as mean \pm SEM. (E) Cross validation of select pitNETenriched transcripts in GFAP $\triangle M e n 1$ PNETs and wild type pancreas. (F) KEGG Ontology Pathway analysis of antra from wild type and $G F A P^{\triangle M e n 1}$ mice showing the number of genes mapped to enriched pathways and their level of statistical significance. (G) Heatmap showing enrichment of kinesin motor protein transcripts in GFAP ${ }^{M e n l}$ pitNETs. (H) Heatmaps depicting downregulation of cytokeratins and (I) immune-related transcripts in $G F A P^{\triangle M e n 1}$ antral extracts. $\mathrm{n}=4-5$ mice per group with the exception of wild type pituitary group which represents four samples of three pooled pituitaries for a total of 12 tissues in this group. 


\section{GRAPHICAL ABSTRACT}

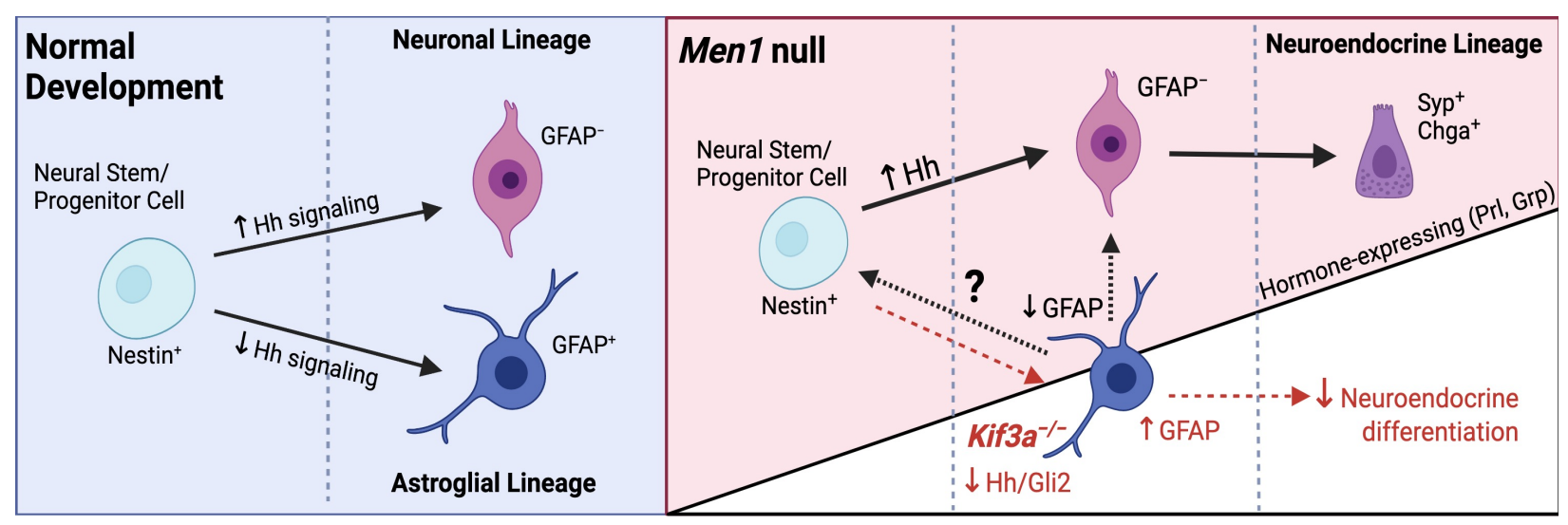


Table 1. Number of mice with macroscopic phenotypes and age/sex-dependent differences

\begin{tabular}{lllll}
\hline Men1 & $\begin{array}{l}\text { Pancreatic } \\
\text { hyperplasia/tumor }\end{array}$ & $\begin{array}{l}\text { Pituitary } \\
\text { Adenoma }\end{array}$ & $\begin{array}{l}\text { Antral } \\
\text { hyperplasia/tumor }\end{array}$ & $\begin{array}{l}\text { BG/Duodenal } \\
\text { Polyp }\end{array}$ \\
\hline WT & 0/20 Avg. age 17.5 mo & $0 / 20$ & $0 / 20$ & $0 / 20$ \\
FL/+ & 1/9 Avg. age 17.9 mo & $\begin{array}{l}\text { 1/9. Male } \\
1 / 7 \text { Female }\end{array}$ & $1 / 9$ & $1 / 9$ \\
& & & & \\
FL/FL & $\begin{array}{l}7 / 26 \text { Avg. age 17.9 mo } \\
\text { 7/12 18mo and older }\end{array}$ & $\begin{array}{l}15 / 29 \\
1 / 7 \text { Male }\end{array}$ & $2 / 26$ \\
& $0 / 14$ Under 18mo & & \\
\hline
\end{tabular}




\section{Figure 1.}
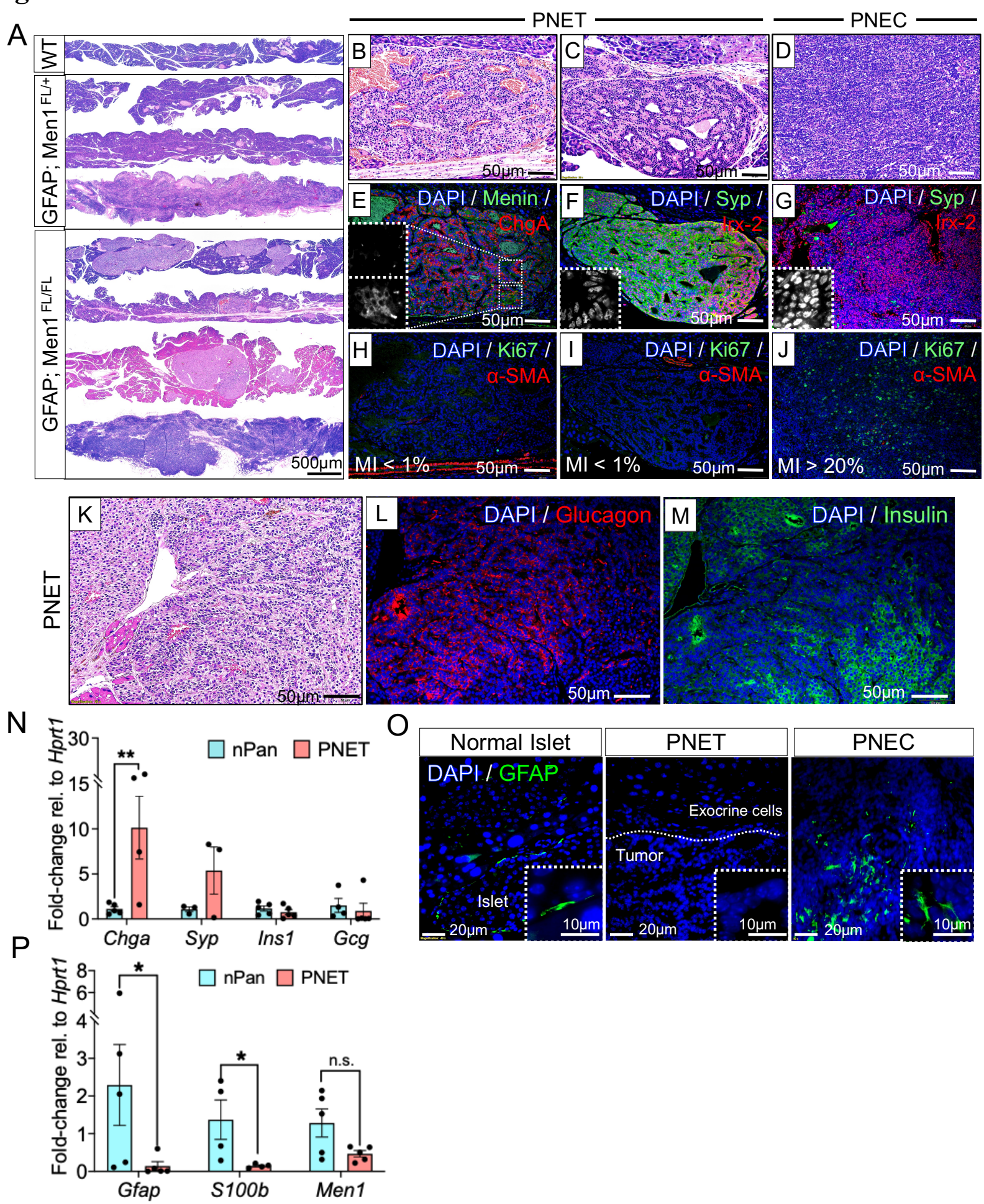


\section{Figure 2.}

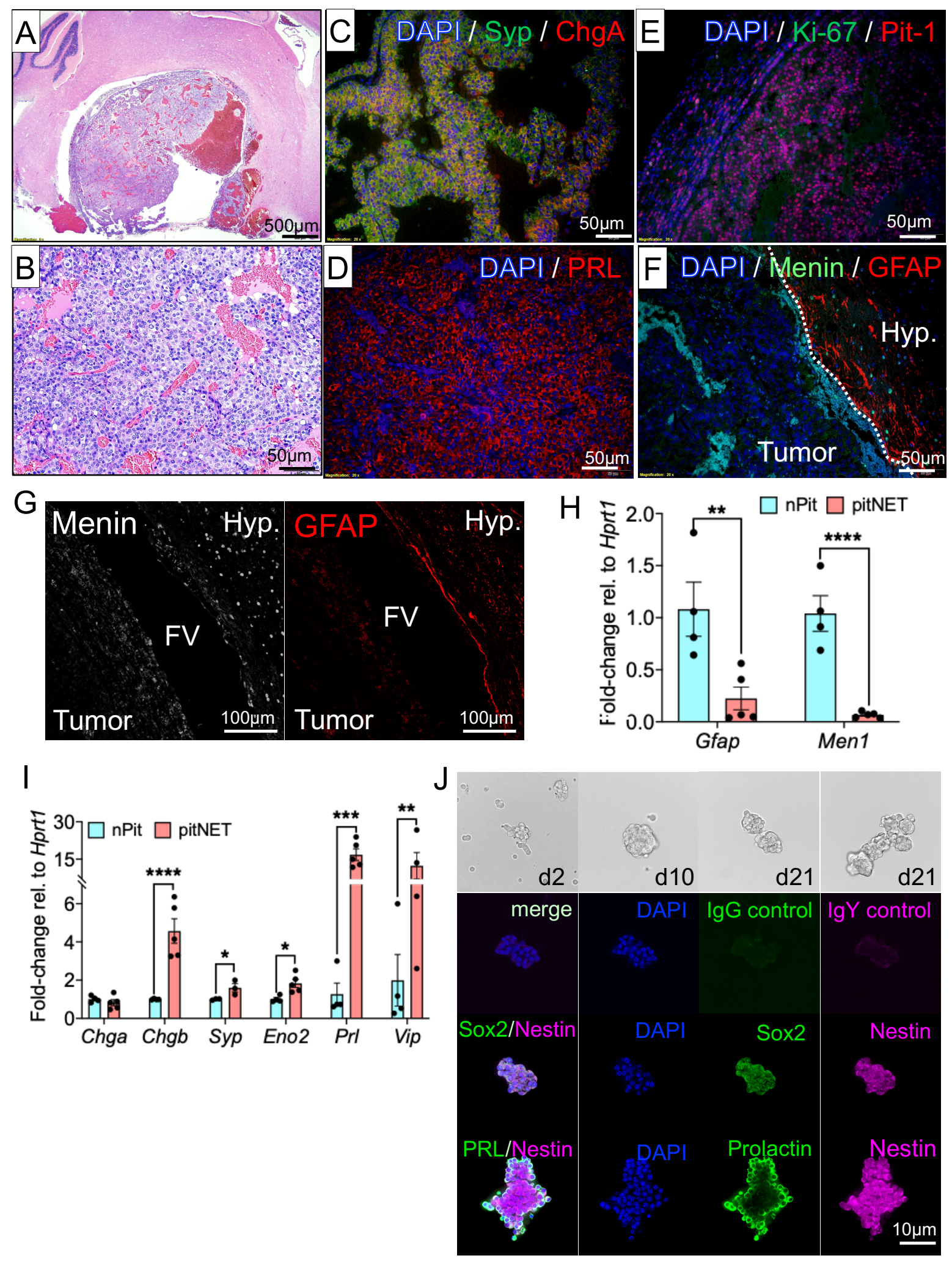


Figure 3.

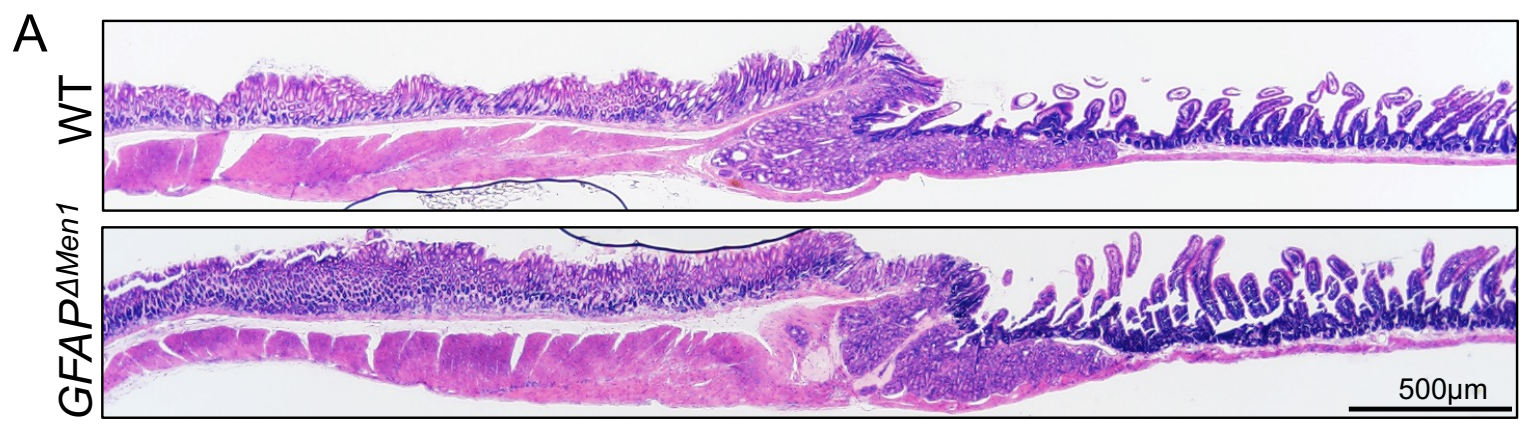

B

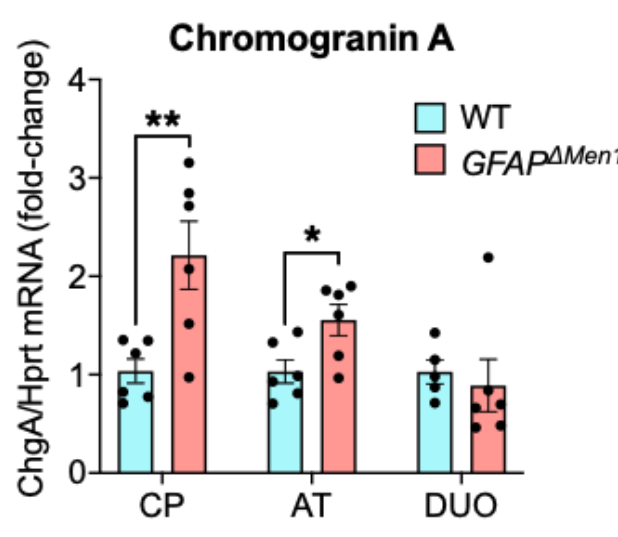

D

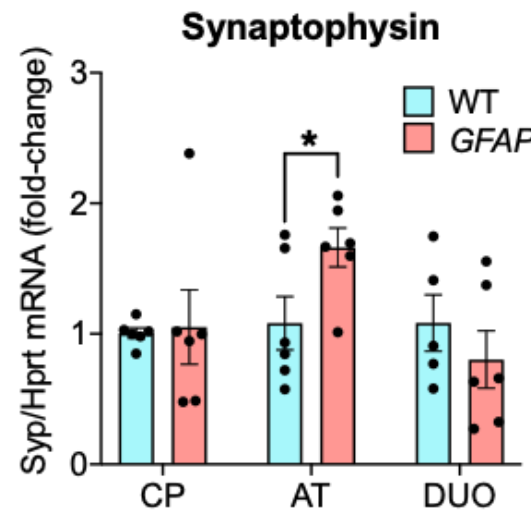

$F$

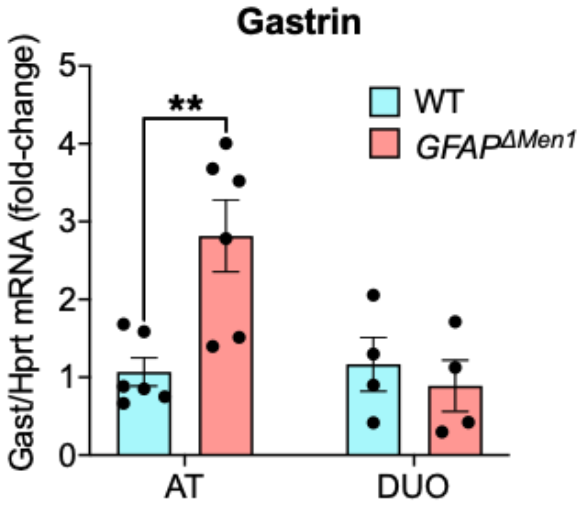

C

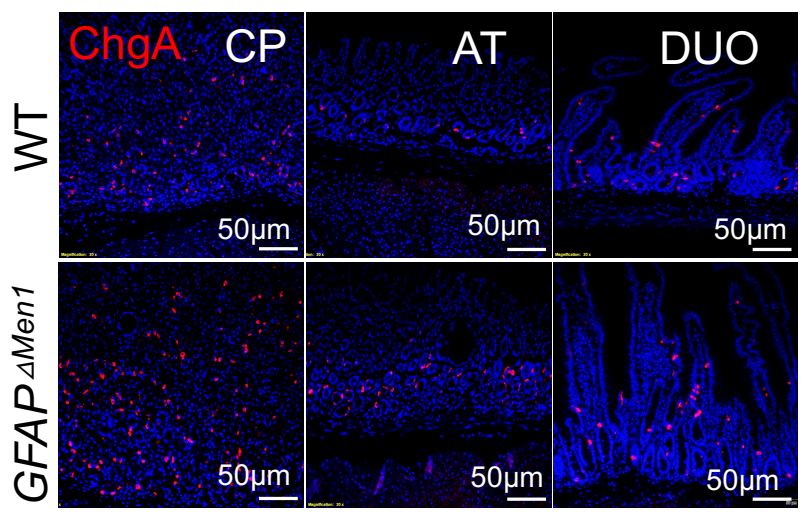

E

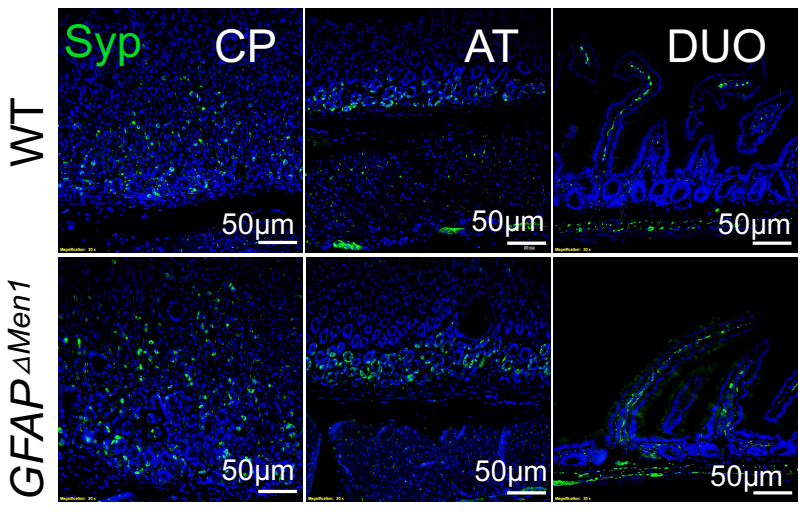

$\mathrm{G}$

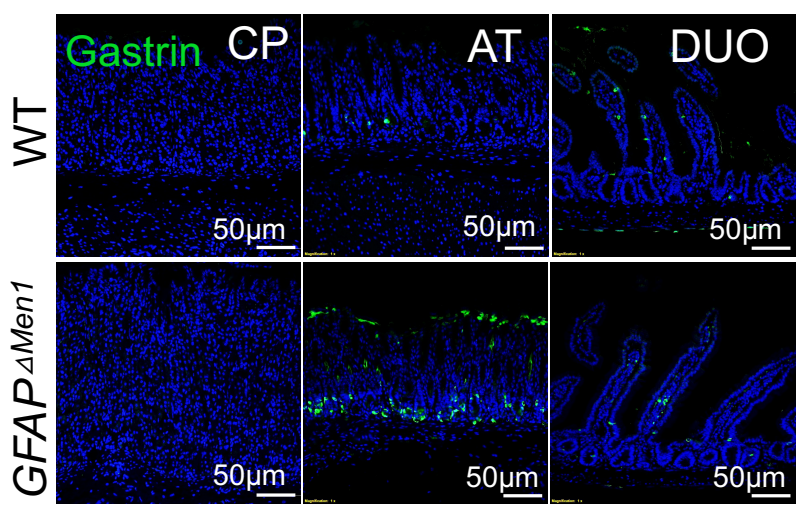




\section{Figure 4.}

A

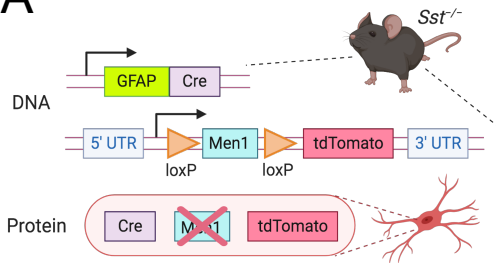

D Cre negative GFAP-tdTomato

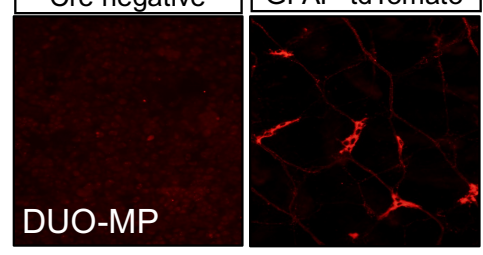

F

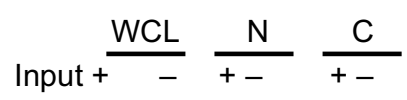

IP: Menin $\alpha$-GFAP (50 kDa)

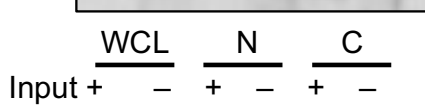

IP: GFAP $\quad+\quad+\quad+\quad+$
$\begin{array}{r}\alpha-M e n i n \\ (70-80 \mathrm{kDa})\end{array}$
B

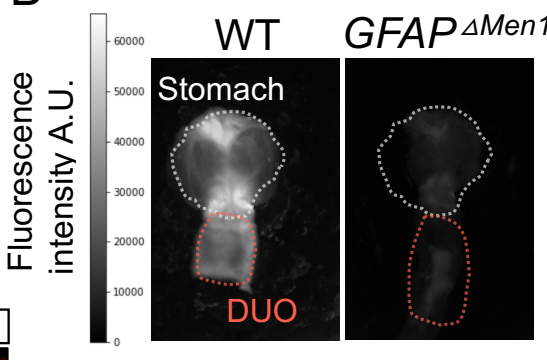

C
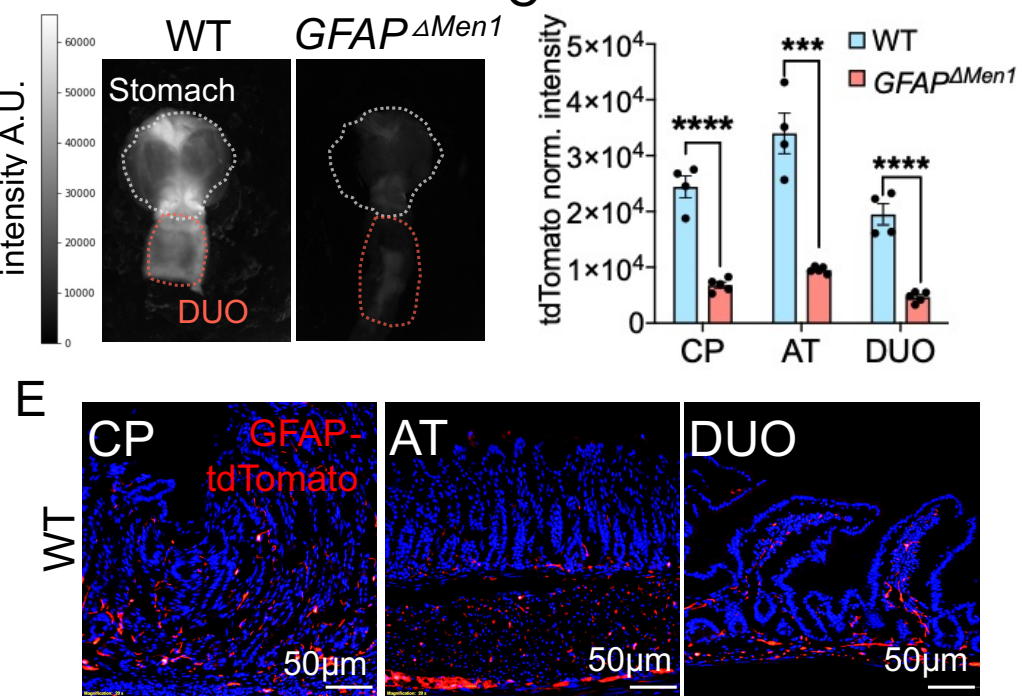

\section{AT}

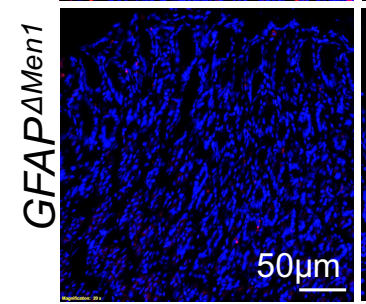

$50 \mu \mathrm{m}$

DUO

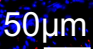

$50 \mu \mathrm{m}$
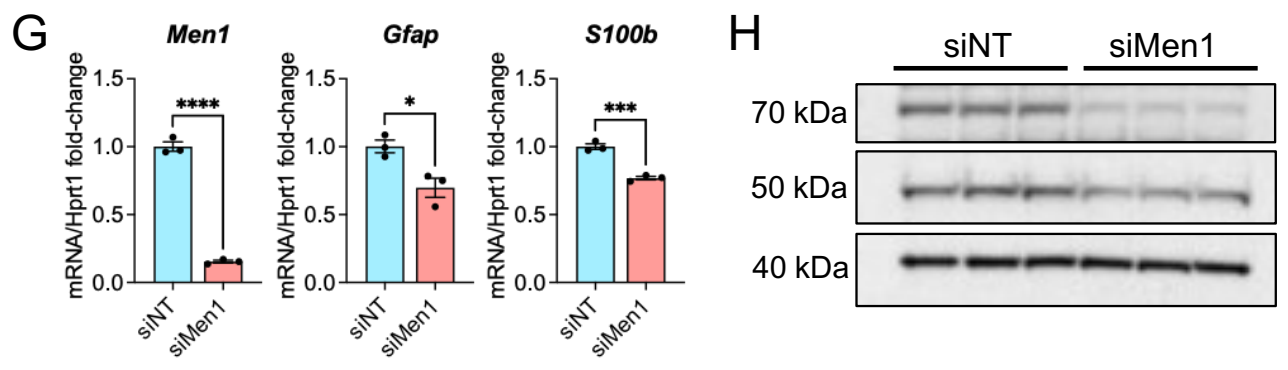

Menin

GFAP

GAPDH 


\section{Figure 5.}

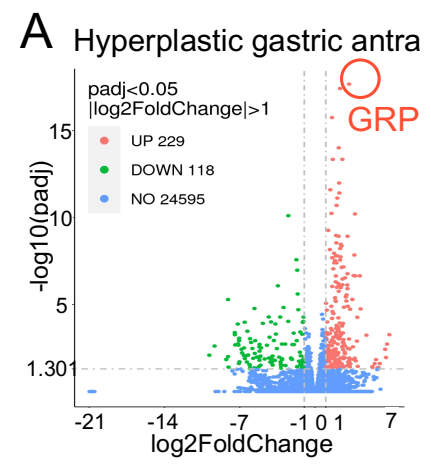

C

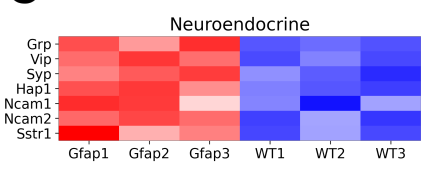

E

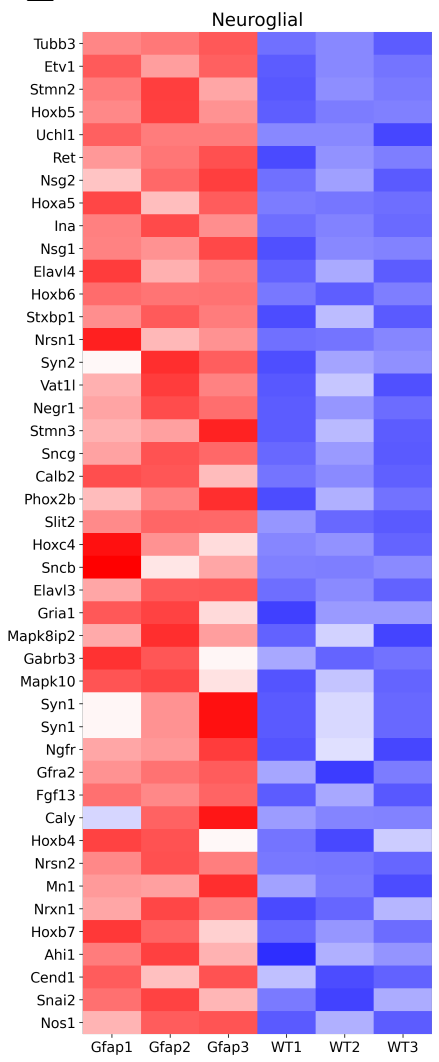

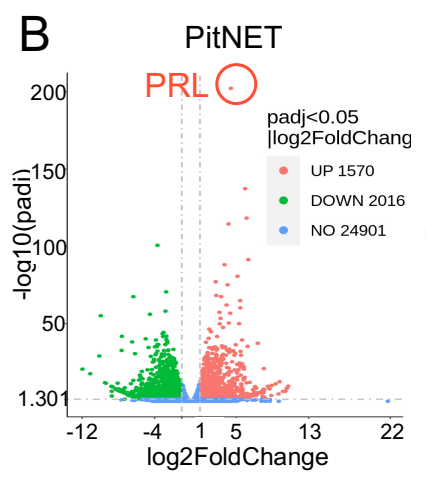

D

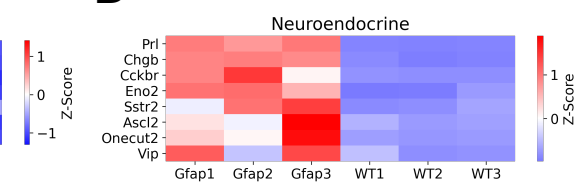

$\mathrm{F}$

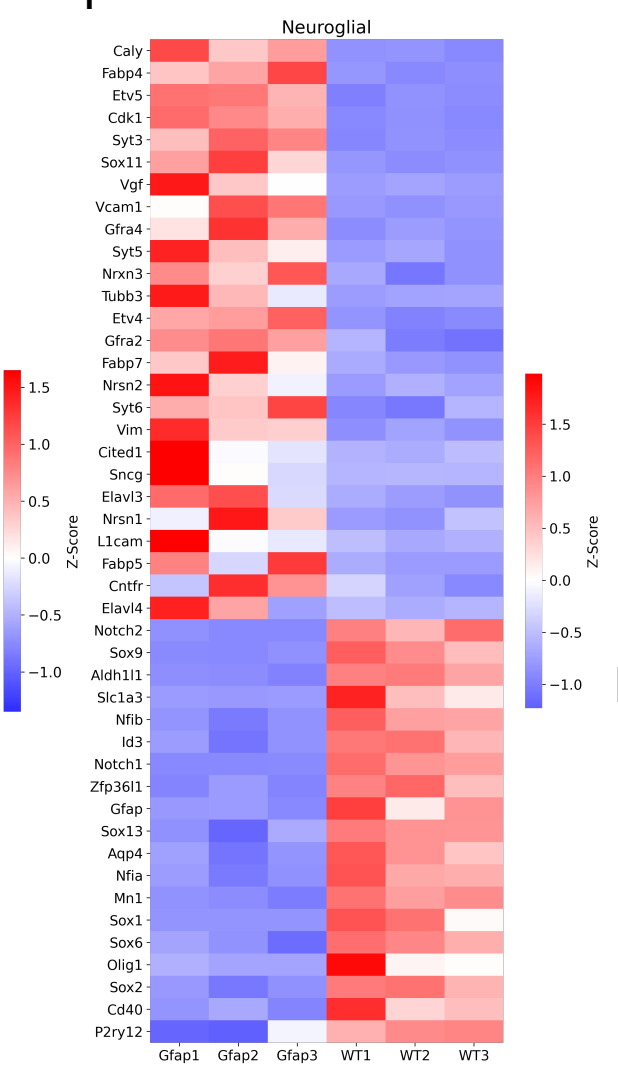

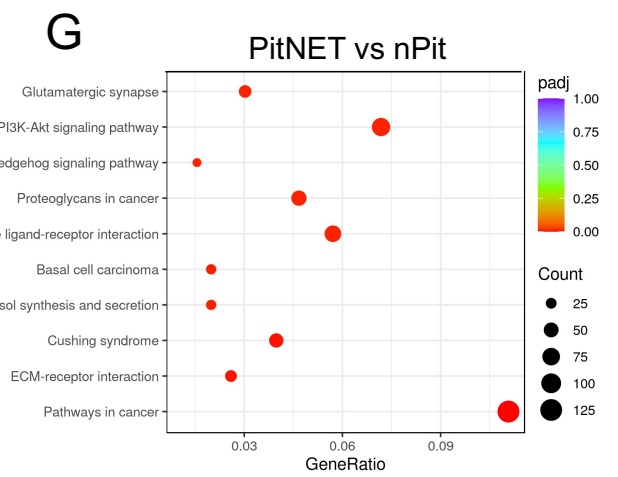

$\mathrm{H}$
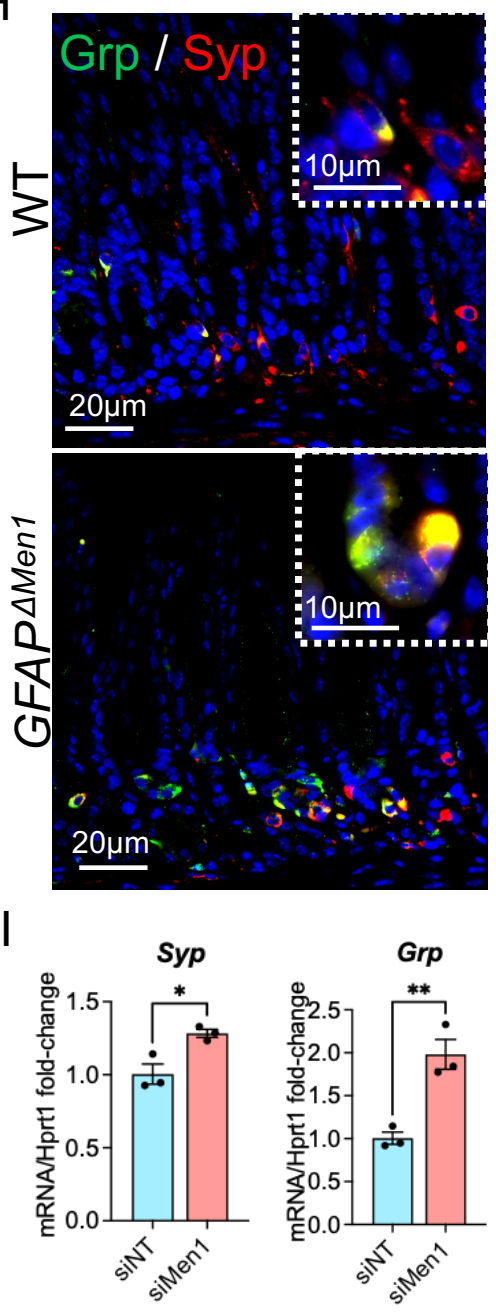


\section{Figure 6.}

A

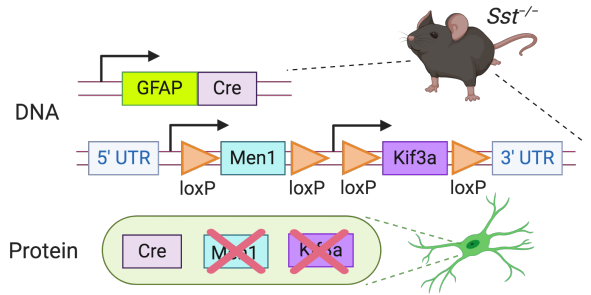

C

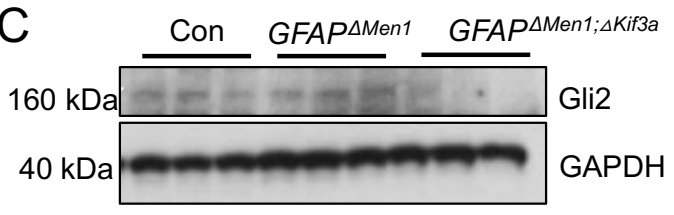

D

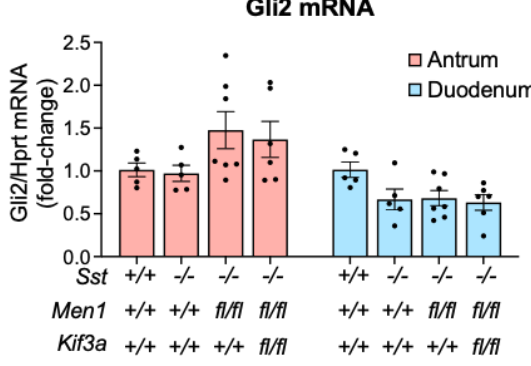

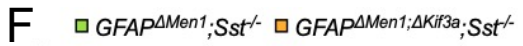
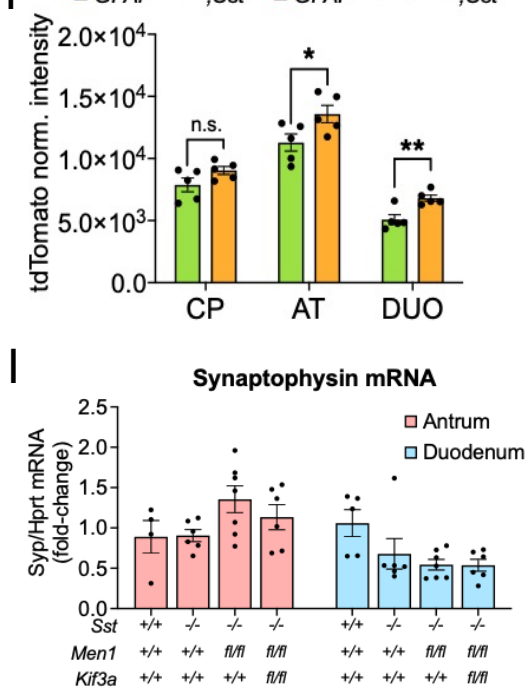

\section{G}

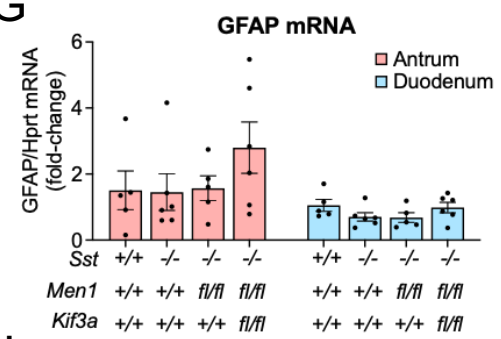

$J$

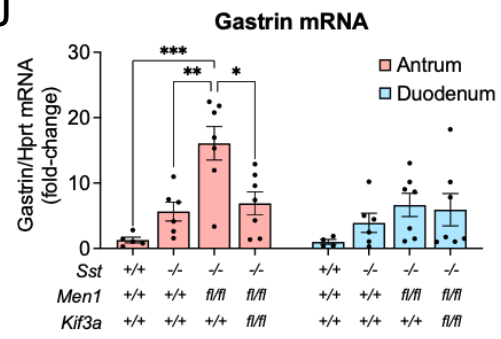

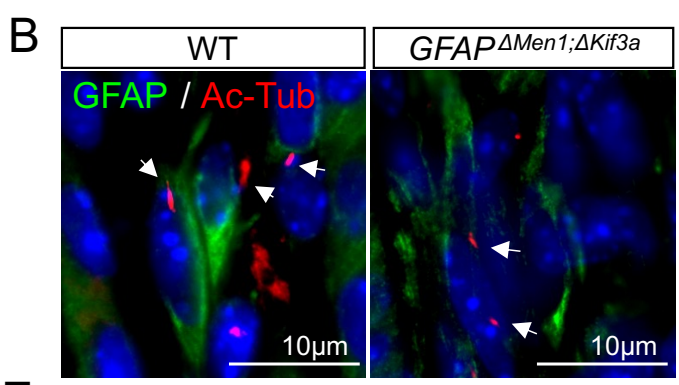

E

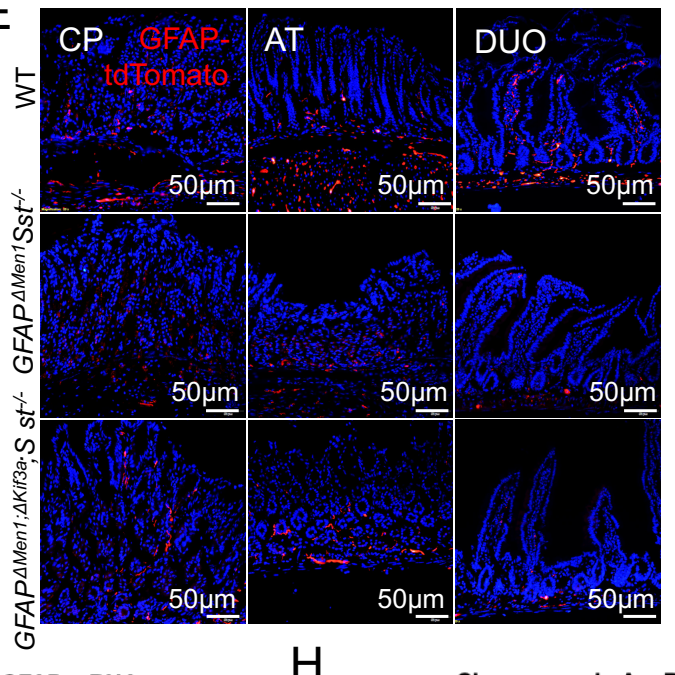

H Chromogranin A mRNA

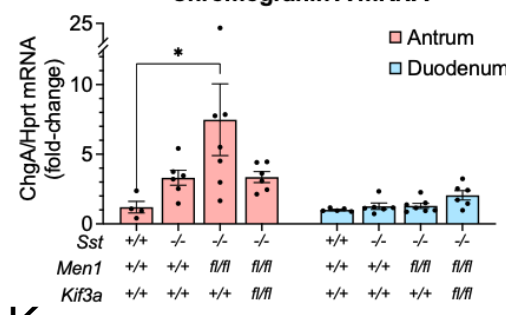

K

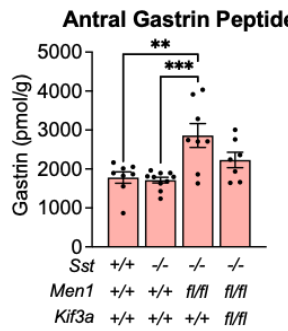




\section{Supplementary Figure 1.}

A

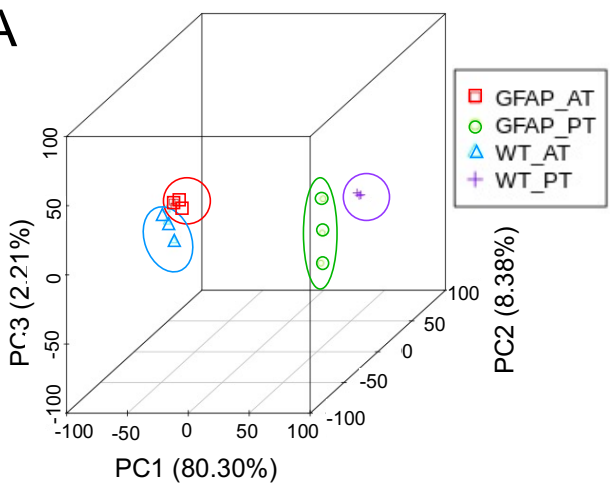

B

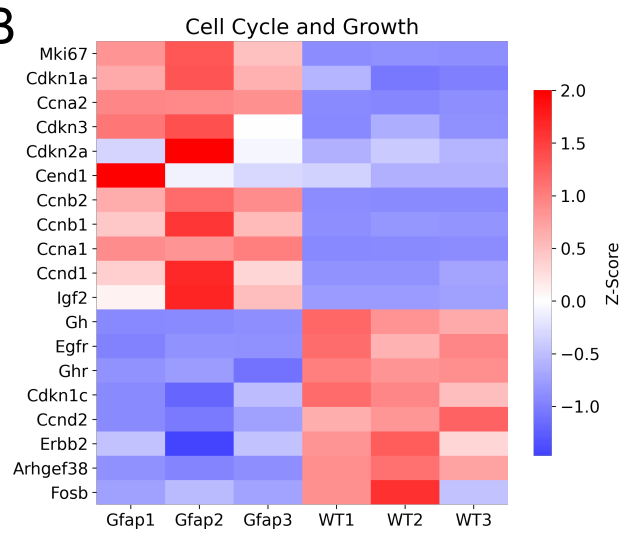

C

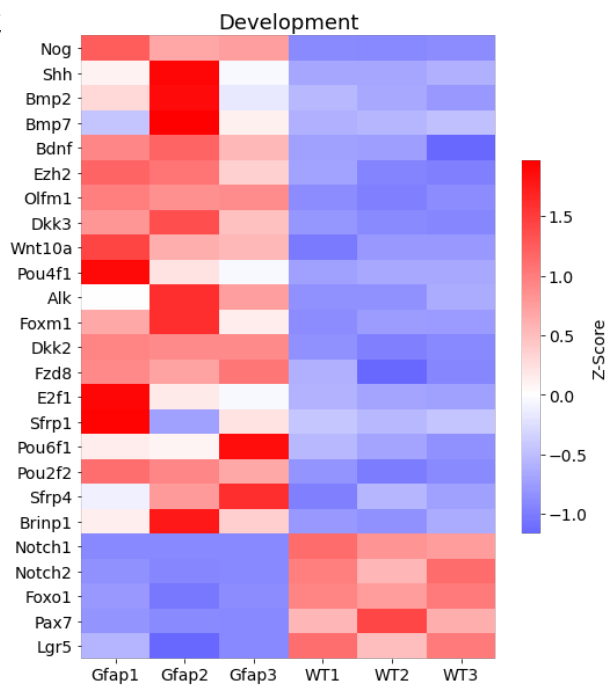

D ${ }_{25} \square$ nPit $\square$ PitNET

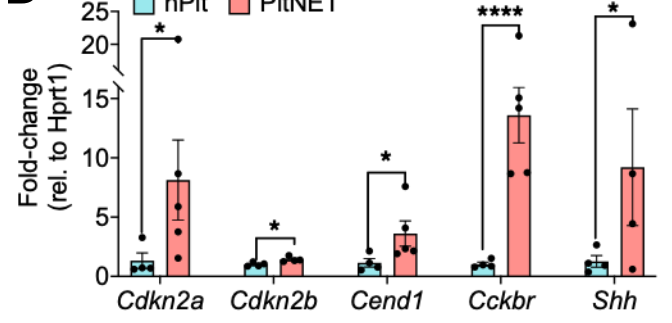

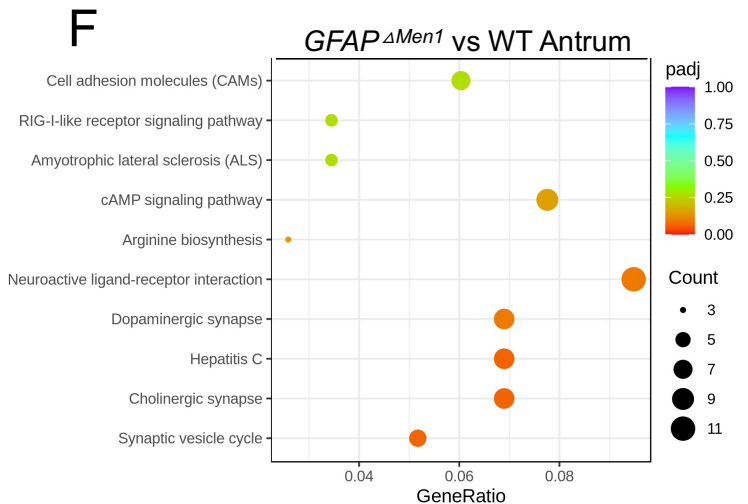

G

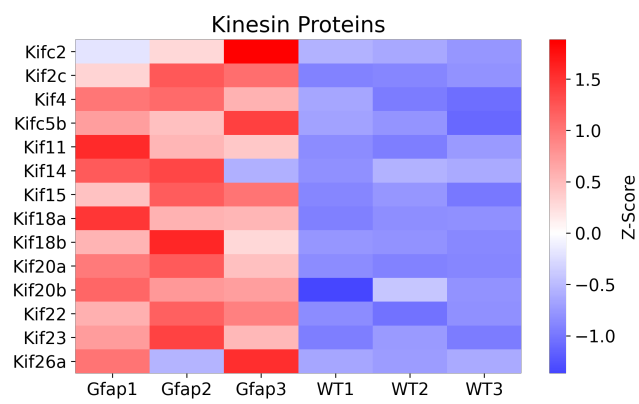

$\mathrm{H}$

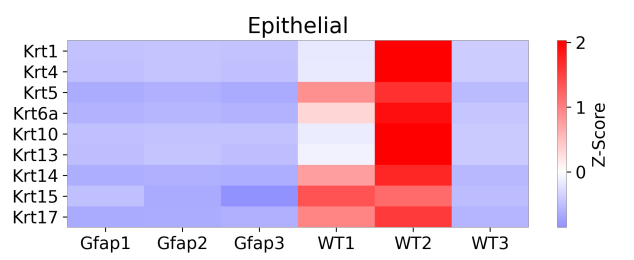

I

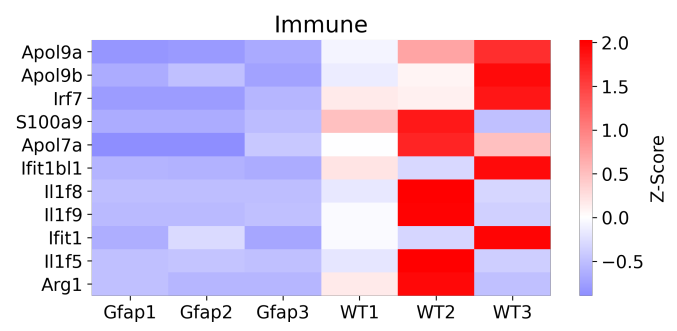

E

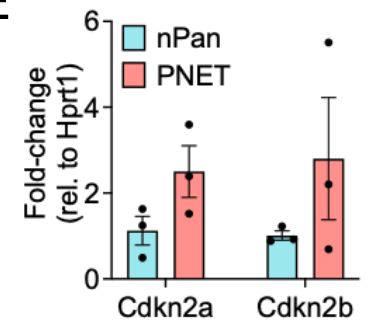

